\title{
Preclinical Evaluation of a Newcastle Disease Virus- Vectored Intranasal SARS-CoV-2 Vaccine
}

Manolo Fernandez Díaz

Farmacologicos Veterinarios S.A.C. FARVET

Katherine Calderón

Farmacologicos Veterinarios S.A.C. FARVET

Aldo Rojas-Neyra

Farmacologicos Veterinarios S.A.C. FARVET

Vikram N. Vakharia

University of Maryland Baltimore County

Ricardo Choque-Guevara

Farmacologicos Veterinarios S.A.C. FARVET

Angela Montalvan

Farmacologicos Veterinarios S.A.C. FARVET

Astrid Poma-Acevedo

Farmacologicos Veterinarios S.A.C. FARVET

Dora Rios-Matos

Farmacologicos Veterinarios S.A.C. FARVET

Andres Agurto- Arteaga

Farmacologicos Veterinarios S.A.C. FARVET

Maria de Grecia Cauti-Mendoza

Farmacologicos Veterinarios S.A.C. FARVET

Norma Perez-Martinez

Farmacologicos Veterinarios S.A.C. FARVET

Gisela Isasi-Rivas

Farmacologicos Veterinarios S.A.C. FARVET

\section{Luis Tataje-Lavanda}

Farmacologicos Veterinarios S.A.C. FARVET

Yacory Sernaque-Aguilar

Farmacologicos Veterinarios S.A.C. FARVET

Freddy Ygnacio-Aguirre

Farmacologicos Veterinarios S.A.C. FARVET

Manuel Criollo-Orozco

Farmacologicos Veterinarios S.A.C. FARVET

Edison Huaccachi-Gonzalez 
Farmacologicos Veterinarios S.A.C. FARVET

Elmer Delgado-Ccancce

Farmacologicos Veterinarios S.A.C. FARVET

Doris Villanueva-Pérez

Farmacologicos Veterinarios S.A.C. FARVET

Ricardo Montesinos-Millan

Farmacologicos Veterinarios S.A.C. FARVET

Kristel Gutiérrez-Manchay

Farmacologicos Veterinarios S.A.C. FARVET

Katherine Pauyac-Antezana

Farmacologicos Veterinarios S.A.C. FARVET

Ingrid Ramirez-Ortiz

Farmacologicos Veterinarios S.A.C. FARVET

Stefany Quiñones-Garcia

Farmacologicos Veterinarios S.A.C. FARVET

Yudith Cauna-Orocollo

Farmacologicos Veterinarios S.A.C. FARVET

Katherine Vallejos-Sánchez

Farmacologicos Veterinarios S.A.C. FARVET

Angela Rios-Angulo

Farmacologicos Veterinarios S.A.C. FARVET

Dennis Núñez-Fernández

Farmacologicos Veterinarios S.A.C. FARVET

Mario I. Salguedo-Bohorquez

Farmacologicos Veterinarios S.A.C. FARVET

Julio Ticona

Farmacologicos Veterinarios S.A.C. FARVET

Manolo Fernández-Sánchez

Farmacologicos Veterinarios S.A.C. FARVET

Eliana Icochea

Farmacologicos Veterinarios S.A.C. FARVET

Luis Guevara-Sarmiento

Farmacologicos Veterinarios S.A.C. FARVET

Mirko Zimic ( $\square$ mirko.zimic@farvet.com )

Farmacologicos Veterinarios S.A.C. FARVET

COVID-19 Working Group in Perú.

Farmacologicos Veterinarios S.A.C. FARVET 


\section{Research Article}

Keywords: SARS-CoV-2, COVID-19, Newcastle disease virus (NDV), neutralizing antibodies, vaccines, intranasal immunization, Spike protein subunit S1, receptor binding domain (RBD)

Posted Date: April 27th, 2021

DOl: https://doi.org/10.21203/rs.3.rs-420780/v1

License: (c) (i) This work is licensed under a Creative Commons Attribution 4.0 International License.

Read Full License 


\section{Preclinical Evaluation of a Newcastle Disease Virus-Vectored Intranasal 2 SARS-CoV-2 Vaccine

4 Manolo Fernandez Díaz ${ }^{1 *}$, Katherine Calderón ${ }^{1}$, Aldo Rojas-Neyra ${ }^{1}$, Vikram N. Vakharia ${ }^{2}$, Ricardo

5 Choque-Guevara ${ }^{1}$, Angela Montalvan ${ }^{1}$, Astrid Poma-Acevedo ${ }^{1}$, Dora Rios-Matos ${ }^{1}$, Andres Agurto-

6 Arteaga $^{1}$, Maria de Grecia Cauti-Mendoza ${ }^{1}$, Norma Perez-Martinez ${ }^{1}$, Gisela Isasi-Rivas ${ }^{1}$, Luis

7 Tataje-Lavanda ${ }^{1}$, Yacory Sernaque-Aguilar ${ }^{1}$, Freddy Ygnacio-Aguirre ${ }^{1}$, Manuel Criollo-Orozco ${ }^{1}$,

8 Edison Huaccachi-Gonzalez ${ }^{1}$, Elmer Delgado-Ccancce ${ }^{1}$, Doris Villanueva-Pérez ${ }^{1}$, Ricardo

9 Montesinos-Millan ${ }^{1}$, Kristel Gutiérrez-Manchay ${ }^{1}$, Katherine Pauyac-Antezana ${ }^{1}$, Ingrid RamirezOrtiz ${ }^{1}$,

10 Stefany Quiñones-Garcia ${ }^{1}$, Yudith Cauna-Orocollo ${ }^{1}$, Katherine Vallejos-Sánchez ${ }^{1}$, Angela A. Rios-

11 Angulo ${ }^{1}$, Dennis Núñez-Fernández ${ }^{1}$, Mario I. Salguedo-Bohorquez ${ }^{1}$, Julio Ticona ${ }^{1}$, Manolo Fernández-

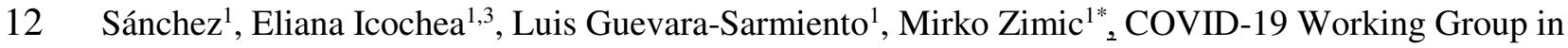

13 Perú.

${ }^{1}$ Farmacológicos Veterinarios S.A.C. FARVET

$17{ }^{2}$ Institute of Marine and Environmental Technology, University of Maryland Baltimore County,

18 Baltimore, USA

$19{ }^{3}$ Laboratorio de Patología Aviar. Facultad de Medicina Veterinaria. Universidad Nacional Mayor de San

20 Marcos, Lima, Perú

* Corresponding authors:

Email: Farvet@farvet.com. Panamericana Sur Nº 766 Km 198.5. Chincha Alta, Ica, Perú. 
42 The COVID-19 pandemic has claimed the lives of millions of people. Vaccination is a critical tool for the 43 control of transmission; however, the recent emergence of potentially vaccine-resistant variants renders it 44 important to have a range of vaccines types. It is desirable that vaccines are safe, effective, easy to 45 administer and store, and inexpensive to produce. Newcastle disease virus (NDV), responsible for 46 respiratory disease in chickens, has no pathogenic homologue in humans. We developed two types of 47 NDV-vectored candidate vaccines, and evaluated them in a SARS-CoV-2 challenge in hamsters.

48 Vaccinations resulted in generation of neutralizing antibodies, prevented lung damage, and reduced viral 49 load and viability. In conclusion, our NDV-based vaccine candidate performed well in a SARS-CoV-2

50 challenge and warrants evaluation in a Phase I human clinical trial. This candidate represents a promising 51 tool in the fight against COVID-19.

KEY WORDS: SARS-CoV-2, COVID-19, Newcastle disease virus (NDV), neutralizing antibodies, vaccines, intranasal immunization, Spike protein subunit S1, receptor binding domain (RBD) 
75 The severe acute respiratory syndrome coronavirus 2 (SARS-CoV-2) recognizes the angiotensin-2

76 converting enzyme (ACE-2), present on the surface of several human cell types including pneumocytes.

77 The glycosylated Spike (S) protein gives the virus the ability to bind to the cell membrane and promote

78 endocytosis, allowing entry of the viral particle ${ }^{1,2}$. The Spike protein is comprised of two subunits, S1

79 and S2. The most distal end of the S1 subunit is the receptor binding domain (RBD), which interacts with

80 ACE-2 through the receptor binding motif (RBM) ${ }^{3}$. Previous studies with SARS-CoV and Middle

81 Eastern respiratory syndrome coronavirus (MERSCoV) have helped to identify potential SARS-CoV-2

82 vaccine candidates, particularly encompassing the $\mathrm{S}$ protein due to its known immunogenicity ${ }^{4-7}$. SARS-

$83 \mathrm{CoV}-2$ has also been found to have potential B and T lymphocyte protective epitopes with the potential

84 for vaccine candidate ${ }^{8,9}$. The S1 and RBD domains are considered important vaccine targets ${ }^{10}$ and have

85 been the focus of vaccine development to date. However, the amino acid sequences of S1/RBD are found

86 to be under a selection pressure, seeking a greater affinity for ACE-2 ${ }^{11-15}$ or escape from neutralization

87 by antibodies against S1 of SARS-CoV-2 ${ }^{16,17}$. Different strategies have been applied for the development

88 of vaccines against SARS-CoV-2, seeking safety, effectiveness and protection against the virus,

89 including vaccines based on inactivated virus, those based on mRNA, and those using viral vectors ${ }^{18-21}$.

90 Newcastle disease virus (NDV), the causative agent of the Newcastle disease (ND), has been used as a

91 viral vector for the expression of diverse antigens from animal and human pathogens ${ }^{22-24}$. NDV is a

92 member of the Paramyxoviridae family, recently known as Avian orthoavulavirus ${ }^{25}$.

93 NDV is a single-stranded, negative-sense RNA virus with a genome size of approximately $15.2 \mathrm{~kb}^{26,27}$.

94 NDV encodes six structural proteins: nucleocapsid protein (NP), phosphoprotein (P), matrix protein (M),

95 fusion protein $(\mathrm{F})$, haemagglutinin-neuraminidase protein $(\mathrm{HN})$, and the large protein $(\mathrm{L})$, which is a

96 viral polymerase ${ }^{26,27}$.

97 NDV can be divided into three groups according to their virulence in poultry: velogenic, mesogenic, and

98 lentogenic ${ }^{26}$. NDV strain LaSota is lentogenic, and it is routinely used as a live NDV vaccine. It grows to

99 a high titer in embryonated chicken eggs, induces strong humoral and cellular immune responses, and can

100 be administered via the nasal route ${ }^{27}$.

101 It has been demonstrated in prior studies that NDV does not pose a threat to human health, and the

102 majority of the human population does not have pre-existing immunity ${ }^{23,28,29}$. NDV has selectivity for

103 tumors, acting as an oncolytic virus. Tumoral cell defects, including anti-viral and apoptotic pathways ${ }^{30}$,

104 explain the NDV-mediated oncolytic efficiency in mammal cells, through manipulation of antiviral

105 cellular pathways, induction of apoptosis, and indirect activation of the innate and adaptive immune

106 response (humoral, cellular, and mucosal) $22,31,32$. 
107 NDV has been used as a vector for vaccine development since the late 1990s. The efficiency of vaccines

108 based on this vector has been demonstrated against respiratory viruses, in chickens against infectious

109 bronchitis virus and avian reovirus, in monkeys against SARS-CoV and in camels against MERS-CoV ${ }^{33-}$

$110 \quad{ }^{36}$. These studies have demonstrated that it is feasible to produce $S$ protein from other viruses, especially

111 of SARS-CoV and MERS, which conferred strong immunogenicity and protection in mice and non-

112 humans primates ${ }^{35,36}$. Recently, NDV has been proposed as a potential vector for a vaccine against

113 SARS-CoV-2. Sun, et al. demonstrated in vivo that a NDV-vectored vaccine against SARS-CoV-2

114 administered by the intramuscular route induces a high immune response in mice and hamsters, including

115 reduced weight loss and decreased viral load in the lungs of challenged animals ${ }^{37,38}$. Of note, NDV-

116 vectored vaccines induce mucosal immune response at the respiratory tract, and do not recombine with

117 host DNA during replication ${ }^{35}$.

118 In this study, we describe the design and evaluation of an intranasal NDV-vectored vaccine in hamsters

119 challenged with SARS-CoV-2. The S1 and RBD domains of SARS-CoV-2 spike protein were expressed

120 independently on the surface of a recombinant NDV.

\section{RESULTS}

123 Development and characterization of recombinant NDV expressing SARS-CoV-2 RBD and S1 124 antigens

125 Generation of $r N D V$ s expressing RBD and S1 subunit genes of SARS-CoV-2

126 Vero-E6 cells were co-transfected with full-length plasmid cDNA of constructs pFLC-LS1-HNRBD and

127 pFLC-LS1-S1-F together with three supporting plasmids encoding the NP, P, and L proteins of NDV,

128 essential for the replication of NDV (Figure 1A, 1B). At $72 \mathrm{~h}$ post-transfection, the cells showed several

129 visible plaques with typical cytopathic effect (CPE) from NDV, demonstrating the successful rescue of

130 both recombinant viruses. Supernatants collected five days after transfection were injected into allantoic

131 cavities of 9 day old embryonated specific pathogen free (SPF eggs). The allantoic fluid was harvested

132 four days after inoculation and analyzed by hemagglutination (HA) assays using chicken red blood cells.

133 We found positive HA titers ranging from 2 to 2048.

134 The presence of the HN-RBD and S1-F expression cassettes inserted into the non-coding region between

135 the $\mathrm{P}$ and M genes of the NDV genome was verified by RT-PCR, yielding fragments of 1600 and 3028

136 bases pairs (bp), which were subsequently amplified and sequenced using junction primers NDV-3LS1-

137 2020-F1 and NDV-3LS1-2020-R1, demonstrating proper insertion into the NDV genome (Figure 1C).

138 The new recombinant NDV viruses were named rLS1-HN-RBD and rLS1-S1-F, respectively. 
140 with a molecular mass of $\sim 90 \mathrm{kDa}$ (S1-F) and $\sim 30 \mathrm{kDa}$ (HN-RBD) were detected in cell lysates

141 infected with rLS1-S1-F and rLS1-HN-RBD viruses respectively (Figure 2A). Two protein bands

142 were detected in the purified recombinant virus (Figure 2B), confirming that the S1-F or HN-RBD

143 proteins were incorporated into the viral particles of rLS1-S1-F and rLS1-HN-RBD viruses

144 respectively. These protein bands were not detected in the rLS1-infected cells or in purified viral

145 particles from the rLS1 virus.

146 The expression of the SARS-CoV-2 RBD and S1 subunit was detected in Vero-E6 cells infected with

147 rLS1-HN-RBD, and rLS1-S1-F by Immunofluorescence assay. RBD and S1 subunit expression was not

148 detected in cells infected with the rLS1 virus. NDV protein expression was detected using a chicken

149 antiserum specific to NDV, and a Goat Anti-Chicken IgY H\&L-Alexa Fluor 488 in Vero-E6 cells

150 infected with rLS1, rLS1-HN-RBD, and rLS1-S1-F viruses (Figure 2C).

151 Detection of SARS-CoV-2 S1 subunit or RBD on the viral surface of rLS1-S1-F and rLS1-HNRBD

152 viruses bound to Vero E6 cells was confirmed by flow cytometry in two independent experiments (Figure

153 2D). For the rLS1-S1-F virus, 40.4\% positive cells were detected, for the rLS1HN-RBD virus $10.2 \%$

154 positive cells were detected, and for the rLS1 virus up to $0.37 \%$ positive cells were detected. A higher

155 percentage of cells was detected in the rLS1-S1-F virus than the rLS1-HNRBD virus.

157 Immunogenicity in hamsters

158 Intranasal vaccination elicits specific antibodies against $S$ protein and neutralizing antibodies against

159 SARS-CoV-2 in hamsters

160 Fifteen days after prime immunization, the hamster groups immunized with the live rLS1-HN-RBD,

161 rLS1-S1-F, and the combined rLS1-HN-RBD/rLS1-S1-F vaccines developed specific serum IgG

162 antibodies against S1 and RBD (Figure 3A). At 15 days post-boost (30 days post-immunization) there

163 was a significant increase in the titers of serum IgG antibodies. The control group did not induce SARS-

164 CoV-2 S1 or RBD-specific serum IgG antibodies. Immunization with rLS1-S1-F induced a significantly

165 higher level of S1 and RBD-specific serum IgG antibodies at 15 days postboost when compared to rLS1-

166 HN-RBD and the combined of rLS1-HN-RBD/rLS1-S1-F vaccines (Figure 3B-3C).

167 Neutralization assays using the surrogate virus neutralization test (sVNT) indicated that the sera of groups

168 immunized with rLS1-HN-RBD, rLS1-S1-F, and rLS1-HN-RBD/rLS1-S1-F developed neutralizing

169 antibodies specific to RBD protein at 15 days post-immunization and 15 days postboost. However, the

170 sera from hamsters vaccinated with rLS1-S1-F and rLS1-HN-RBD/rLS1-S1-F showed a percentage of

171 inhibition of the RBD-ACE2 binding greater than 50\% whereas the LS1HN-RBD group only showed 
$17230 \%$ inhibition up to 15 days post-boost. Sera of the control group remained below $20 \%$ up to 15 days

173 post-boost and did not show neutralizing antibodies against the RBD protein (Figure 3D).

174 Pooled serum from hamsters vaccinated with the rLS1-S1-F virus showed a strong titer of viral plaque 175 reduction in the neutralization assay (PRNT) at 15 days post-boost, retaining $100 \%$ of this capacity even 176 at higher dilutions of serum (1/160). The combined rLS1-HN-RBD/rLS1-S1-F vaccine showed a lower 177 titer of viral plaque reduction (1/40), and rLS1-HN-RBD had no effect on viral plaque formation (Figure $178 \quad 3 \mathrm{E}-3 \mathrm{~F})$.

179 Cellular immunity: Cytokines quantification by ELISA

180 Immunization of hamsters did not induce a significant increase in serum levels of IL-2 or IFN $\gamma$, evaluated 181 by quantitative ELISA. Levels of IL-2 (Figure 4A) did not show a significant increase with rLS1-HN182 RBD $(\mathrm{P}=0.55)$, rLS1-S1-F $(\mathrm{P}=0.07)$ or rLS1-HN-RBD/rLS1-S1-F $(\mathrm{P}=0.07)$. However, one of the 183 individuals analyzed which had been vaccinated with rLS1-HN-RBD/rLS1-S1F had high levels of 184 circulating IL-2. Levels of IFN $\gamma$ (Figure 4B) did not increase significantly with rLS1-HN-RBD (P = 185 0.08), rLS1-S1-F (P = 1.00) or rLS1-HN-RBD/rLS1-S1-F ( $=0.56)$. Levels of IL-4 and IL-10 were 186 below the lower limit of detection, and for $\mathrm{TNF} \alpha$ values were low and were detectable only in serum 187 from animals immunized with rLS1-S1-F and rLS1-HN-RBD/rLS1-S1-F (Supplementary Figure 1).

188 Cellular immunity: Cytokines quantification by $q P C R$

189 No significant difference in cytokine gene expression was observed for any of the vaccines used (Figure 190 4C-4D-4E): for rLS1-HN-RBD (IFN $\gamma$ 1.2-fold, $\mathrm{P}=1.00$, TNF $\alpha$ 1.48-fold, $\mathrm{P}=0.16$, IL-10 1.7fold, $\mathrm{P}=0.16$ ), 191 rLS1-S1-F (IFN $\gamma$ 1.16-fold, $\mathrm{P}=0.16$, TNF $\alpha$ 1.48-fold, $\mathrm{P}=0.14$, IL-10 P=0.16) or rLS1HN-RBD + rLS1-

192 S1-F (IFN $\gamma$ 0.81-fold, $\mathrm{P}=0.48$, TNF $\alpha$ 1.12-fold, $\mathrm{P}=0.48$, IL-10 0.90, P=0.48).

\section{Efficacy of the vaccines against SARS-CoV-2 challenge}

194 On days 2 and 5 post-challenge with the SARS-CoV-2, a positive SARS-CoV-2 isolate was obtained 195 from $100 \%$ of the unvaccinated control group in Vero cell culture, and by day 10 none of the hamsters 196 had a positive isolate. Viral isolation and IFA showed that rLS1-S1-F and the combined rLS1-S1-F/rLS1197 HN-RBD vaccine elicited good responses, with no virus isolated from any of the vaccinated hamsters and 198 negative IFA detection in the lung tissue at days 5 and 10 postchallenge. The rLS1-HN-RBD vaccine 199 alone did not demonstrate sufficient neutralizing capacity to prevent the infection: virus isolates were 200 obtained at day 5 post-challenge, confirmed by IFA in lung tissue, in 100\% of the hamsters that received 201 this vaccine (Figure 5A). 
202 Viral quantification by RT-qPCR of the viral isolate obtained from hamster lung homogenates grown in

203 Vero cells confirmed the presence of a high viral load (Ctp: 12) in unimmunized (control) hamsters and

204 hamsters immunized with the rLS1-HN-RBD and rLS1-HN-RBD/rLS1-S1-F vaccines at day 2 post-

205 challenge. Animals immunized with rLS1-S1-F showed a lower viral load (Ctp: 25). At day 5 post-

206 challenge, the viral load from the isolate was maintained in the control group and in hamsters immunized

207 with rLS1-HN-RBD, however, in hamsters immunized with rLS1-S1-F and rLS1-HN-RBD/rLS1-S1-F

208 the viral load decreased significantly (Ctp: 28-31, P <0.05, Figure 5B). On day 10 post-challenge all of

209 the groups analyzed, including the control, presented a low viral load (Ctp: 32-34) (Figure 5B), probably

210 due to the presence of residual RNA, since we did not detect any cytopathic effect on Vero cell culture.

211 The histopathological status of the hamster lungs was monitored during the SARS-CoV-2 challenge. The

212 unvaccinated (control) group demonstrated pathological signs of the disease, starting with interstitial

213 pneumonia at 2 days post-challenge, evolving into hemorrhagic pneumonia at 5 days post-challenge, and

214 ending up in severe bronchopneumonia, characterized by a thickening in the parenchyma wall, greater

215 infiltration of inflammatory cells, and in bronchioles lumen, and loss of alveolar architecture. The groups

216 immunized with rLS1-S1-F and rLS1-HN-RBD/rLS1-S1-F vaccines did not show visible lesions,

217 maintaining characteristics of the lung tissue similar to those seen in the unchallenged group at each of

218 the evaluated points. However, the group immunized with rLS1-HN-RBD vaccine developed pathology

219 that was less severe than that seen in the unvaccinated group, with pneumonia present at 2 days post-

220 challenge and ending in a moderate to severe pneumonia at 10 days (Figure 5C).

221 Unvaccinated animals belonging to the unchallenged control group showed an average percentage

222 variation in body weight of no more than $3 \%$ over the 10 days of analysis. Unvaccinated animals that

223 were infected with SARS-CoV-2 showed significant weight loss, with an average reduction in body

224 weight of over $5 \%$ on day 5 and over $10-25 \%$ on day 10 . There were no statistically significant

225 differences between the weight of vaccinated and unvaccinated, unchallenged hamsters on days 2 and 5,

226 but there was a significant difference between the challenged control group and the rLS1-HN-RBD/rLS1-

227 S1-F vaccinated group at day 10 (Figure 6A).

228 Assessments of the animals' average speed, acceleration, and displacement confirmed that hamsters

229 vaccinated with the combined rLS1-S1-F/rLS1-HN-RBD vaccine were the most mobile on day 5 (time at

230 which symptoms appear) and day 10 (time at which symptoms disappear) post-challenge. Animals

231 vaccinated with the combined rLS1-S1-F/rLS1-HN-RBD vaccine showed the greatest recovery in terms

232 of mobility (Figure 6B-6C-6D). 


\section{DISCUSSION}

235 In this study, we developed two recombinant NDV nasal vaccine candidates expressing the SARSCoV-2

236 S1 and RBD antigens. The vaccine candidate expressing S1 showed favorable results during its

237 evaluation in the pre-clinical phase.

238 Efficacy assessment in hamsters showed that the vaccine was able to effectively protect the animals

239 against the SARS-CoV-2 targets, S1 and RBD antigens: the lungs of vaccinated animals did not show

240 any evidence of cell damage, and the viral load as well as viral viability were considerably lower in the

241 vaccinated group compared to the control group. In keeping with these results, the vaccinated animals

242 showed significantly greater mobility than the control group, and showed no evidence of weight loss, in

243 contrast to what was observed in the control group. Together with these encouraging results, that this is a

244 nasal vaccine that is easy to administer, is lyophilized and stable in storage at $4^{\circ} \mathrm{C}$, and is a relatively fast

245 and economical vaccine to produce, make this vaccine candidate a promising tool to contribute to the

246 fight against the pandemic.

247 The RBD domain, and in particular the RBM motif, are the regions of the spike protein that directly

248 interact with the ACE2 receptor to initiate the infection process, and therefore constitute the most

249 important target for neutralizing antibodies ${ }^{39,40}$. Recent studies have shown that in COVID-19

250 convalescent patients, neutralizing antibodies are commonly directed against specific epitopes of the

251 RBD domain ${ }^{39,40}$.

252 Three nasal vaccine candidates were evaluated in this study. One was an NDV presenting the RBD

253 domain (rLS1-HN-RBD), the second was an NDV presenting the S1 subunit (rLS1-S1-F), which includes

254 the RBD domain, and the third was a mixture of both rLS1-HN-RBD and rLS1-S1-F. The strongest

255 immunity and protection were elicited by the rLS1-S1-F vaccine, followed by the combined rLS1-HN-

256 RBD/ rLS1-S1-F vaccine. Surprisingly, the rLS1-HN-RBD vaccine did not show any evidence of

257 protection. There are at least two possible explanations that are not necessarily mutually exclusive. First,

258 the S1 subunit may include protective epitopes in addition to those present in the RBD domain, for which

259 neutralizing antibodies could interfere with the SACE2 interaction perhaps at a distant steric level. This

260 possibility is supported by a previous study that showed that the S1 subunit contains neutralizing epitopes

261 not found in the RBD ${ }^{41}$. Second, the RBD present in the rLS1-HN-RBD vaccine does not reach folding

262 close enough to the 3dimensional structure of the biologically active RBD when it is in the SARS-CoV-2

263 viral particle. It is likely that the presence of the additional S1 moiety may provide support for RBD to

264 reach a more comparable folding. Therefore, it is possible that conformational B epitopes may be playing

265 a more important role than linear T epitopes in the protective immune response. A recent study that

266 evaluated a similar vaccine candidate vectored in NDV exposing the complete S antigen (S1 and S2 
267 domains) demonstrated protection of hamsters in a challenge assay ${ }^{38}$. It is likely that the major

268 contribution to the protection observed in these studies is associated with S1, which includes the RBD

269 domain in a protein environment that favors the proper folding, allowing the presentation of appropriate

270 conformational B epitopes.

271 Animals from the unvaccinated control group that were challenged with SARS-CoV-2 positive virus

272 cultures at 2 and 5 days post challenge (dpc), which became negative at day 10 . This is consistent with

273 previous studies, which reported that viral load is reduced to undetectable levels by 8 days after infection

274 in the hamster model ${ }^{42,43}$. Along with the culture results, the IFA test also confirmed that the rLS1-S1-F

275 vaccine, followed by the combined rLS1-HN-RBD/ rLS1-S1-F vaccine, induced the strongest protective

276 responses, evidenced by failure to isolate virus from the lung tissue at $5 \mathrm{dpc}$. At $2 \mathrm{dpc}$, only half of the

277 animals vaccinated with the rLS1-S1-F vaccine had virus isolated, and these had a negative IFA. This

278 suggests that inactivation of the inoculated SARS-CoV-2 virus is likely to be occurring between 2 and 3

$279 \mathrm{dpc}$ in the hamster model.

280 Histopathological evaluation of the non-vaccinated hamsters' lungs after the challenge showed severe

281 pathological signs of the disease, beginning with interstitial pneumonia $2 \mathrm{dpc}$, evolving to hemorrhagic

282 pneumonia, and ending in severe bronchopneumonia, as well as the loss of alveolar architecture. In

283 contrast, the groups immunized with rLS1-S1-F and rLS1-HN-RBD/rLS1-S1-F were protected, showing

284 almost intact alveoli, capillaries, and respiratory capillaries, without evidence of an inflammatory

285 reaction. However, the animals vaccinated with rLS1-RBD-HN developed pathological lesions, although

286 with a lesser hemorrhagic degree than the non-vaccinated control group, with pneumonia at $2 \mathrm{dpc}$ and

287 ending in a moderate to severe pneumonia at $10 \mathrm{dpc}$. Recent studies reported that Golden Syrian

288 hamsters inoculated by the intranasal route with $8 \times 10^{4}$ TCID $_{50}$ SARS-CoV-2 show efficient virus

289 replication in the respiratory epithelium associated with a reduction in the number of replicating olfactory

290 sensory neurons of the nasal mucosa at $2 \mathrm{dpc}^{43}$, however, virus clearance is observed from 7-10 dpc ${ }^{42,43}$.

291 The ability of the rLS1-S1-F vaccine to neutralize the SARS-CoV-2 virus, block its replication in the cell

292 culture between 2 and $5 \mathrm{dpc}$, and reduce its presence in the lungs according to the IFA assay, suggests

293 that the rLS1-S1-F vaccine may reduce virus transmission from $2 \mathrm{dpc}$ in the hamster model. This is an

294 encouraging result that needs to be verified in human clinical trials.

295 In the hamster challenge trial, the animals in the non-vaccinated control group lost significant body

296 weight (10-25\%) during the 10-day trial period. Animals vaccinated with rLS1-S1-F showed a minor

297 body weight variation similar to that of the uninfected (mock) group, suggesting a protective effect of this

298 vaccine candidate. 
299 In this study, we evaluated for the first time the mobility pattern of the animals as an objective and

300 quantitative indicator of their health status. Using recorded videos and computational tools for pattern

301 analysis and digital tracking, we measured the average velocity, the average acceleration, and the average

302 displacement of the animals in their cages at 2, 5, and $10 \mathrm{dpc}$. The results showed that at $5 \mathrm{dpc}$, the

303 animals from the unvaccinated control group had a reduced average displacement, velocity, and

304 acceleration compared to the vaccinated animals. This marked difference was not clearly observed at 2

305 dpc, confirming that at that time point, the infected animals may have been relatively asymptomatic.

306 Similarly, at $10 \mathrm{dpc}$ all animals recovered their mobility with no differences observed.

307 This result agrees with other findings that show clearance of the virus at $10 \mathrm{dpc}$.

308 A favorable result that suggests strong protection of the rLS1-S1-F vaccine is the neutralization capacity

309 of the vaccinated hamsters' sera against the SARS-CoV-2 virus at 30 days after immunization in the

310 PRNT test. In contrast, animals vaccinated with rLS1-HN-RBD showed marginal sero-neutralization

311 capacity. This result agrees with similar findings reported in a recent study evaluating an intranasal NDV-

312 vectored live attenuated SAS-CoV-2 vaccine, showing that humoral immunity is induced to high levels in

313 a relatively short time ${ }^{44}$.

314 Respiratory viruses induce a strong response in the respiratory tract mucosa, so vaccines based on the

315 NDV vector should be effective in respiratory diseases and reduce transmission. Likewise, a vaccine

316 candidate for SARS-CoV based on the NDV construct using the S protein confirmed that two doses 28

317 days apart of $10^{7} \mathrm{PFU}$ delivered by the intranasal and intratracheal routes produced significant protection

318 against SARS-CoV in juvenile primates Cercopithecus aethiops ${ }^{35}$. In a recent study, an NDV-vectored

319 nasal vaccine displaying the S protein was able to induce an IgA antibodymediated mucosal humoral

320 response ${ }^{44}$. A mucosal antibody response is considered important against infections that use the

321 respiratory tract as a route of entry, making the respiratory tract mucosa the first line of defense against

322 this infection. Currently, we are completing an assay to evaluate the presence of anti-S1/RBD mucosal

323 IgA antibodies in mice vaccinated with rLS1-S1-F. Preliminary data show evidence of IgA production in

324 bone marrow cells (data not shown). Further studies are required to confirm this finding.

325 Other studies have reported that NDV virus is restricted to the respiratory tract and is not detected in 326 other organs or blood, therefore replication in humans is expected to be limited and benign ${ }^{45,46}$. Rarely,

327 humans exposed to mesogenic NDV have been observed to develop conjunctivitis, laryngitis, or flu-like

328 symptoms that disappear within 1 to 2 days ${ }^{46,47}$. Crucially, safety and toxicity tests were conducted with

329 doses that were not produced under strict GMP certification. That the trials were conducted with non

330 GMP doses of the vaccine means that any adverse events will be over-projected, and lower rates would

331 be expected in an evaluation of the vaccine at doses produced under GMP conditions. 
332 NDV has been repeatedly used in the development of successful vaccines to eliminate infectious diseases 333 in poultry ${ }^{27}$. Currently, there is an NDV strain genotype XII that predominates in Peru, China and 334 Vietnam, which has been used to develop rNDV vaccines ${ }^{48}$. Likewise, Shirvani et al. used the rNDV 335 vector to control infectious bronchitis in free-range chickens, in which the spike $\mathrm{S}$ protein is expressed, 336 showing equal efficacy as the same infectious bronchitis virus vaccine ${ }^{33}$. The LaSota is the attenuated 337 NDV strain most commonly used as a vaccine around the world against NDV infection, with doses of $338 \mathrm{TCID}_{50}$ ranging from $10^{4}$ to $10^{5}$ and which is administered to animals by oral, nasal, ocular, or spray 339 delivery ${ }^{49-51}$. This results in frequent exposure of vaccinators to NDV virus, which ends up being 340 inhaled. Thus, vaccinators and caretakers are frequently exposed to the NDV vector without any reported 341 side effects to date ${ }^{52-54}$. Accumulated doses of NDV inhaled by vaccinators in Chincha-Peru over the last 342 few decades have never resulted in any reported adverse effects in this population (data not shown).

343 The development of the NDV-vectored vaccine candidate presented here includes a final lyophilization

344 step. This confers stability: the vaccine can be stored at $8^{\circ} \mathrm{C}$ for several months without losing more than $3455 \%$ of its activity, similar to other lyophilized vaccines ${ }^{55}$. The fact that the NDV-S1 vaccine is 346 administered through the nasal route gives it a further advantage in simplifying the logistical 347 requirements for immunizations. There is no need for an army of vaccinators or large numbers of 348 syringes. It is possible that doses of rLS1-S1-F vaccine could be delivered in 500-dose vials with a 349 manual trigger-activated dispenser system that uses individual disposable tips. In this way, a nasal 350 vaccine could be delivered in large-scale campaigns in remote rural communities with great ease.

351 The COVID-19 pandemic has the potential to become endemic, and if this were to happen vaccines 352 would need to be routinely administered with some frequency ${ }^{56,57}$. SARS-CoV-2 in recent months has 353 shown an intense level of mutations in the viral antigens used in the various vaccines currently available.

354 These mutations have been selected naturally, in the face of the immunological pressure exerted by 355 individuals cured of COVID-19. Thus, mutations have now been identified that may give the virus the 356 ability to escape acquired immunity (immune resistance), and this may lead to a surge in cases of SARS357 CoV-2 reinfection. These same naturally selected mutations have also been selected in vitro, under 358 immunological selection pressures using convalescent serum neutralizing antibodies.

359 This suggests a high possibility that vaccines based on circulating S1 antigen in the early 2020's may be 360 compromised to some degree in their level of effectiveness against new SARS-CoV-2 variants.

361 Therefore, the most efficient way to deal with the COVID-19 pandemic will be to use vaccines

362 customized for specific geographic areas, based on the distribution of circulating variants over a certain 363 period of time, and which can be produced and administered promptly. The rLS1-S1F vaccine can be 364 upgraded and carry a vaccine antigen corresponding to a more relevant strain in a relatively short time. 
365 NDV can be transformed within 30-45 days, and a master cryobank generated to start producing updated

366 vaccine batches. It is therefore important to have permanent epidemiological surveillance programs to

367 identify any variation in the distribution of circulating strains in a region of interest.

368 In conclusion, we have demonstrated that our rLS1-S1-F vaccine candidate shows promise in preclinical 369 studies. This vaccine candidate was shown to be safe and immunogenic, and provided strong protection 370 against a SARS-CoV-2 challenge. Clinical trials are now needed to evaluate its safety and efficacy in 371 humans.

372

\section{METHODS}

\section{Ethics statements}

375 Animal research was conducted following relevant guidelines and regulations. All experimental protocols 376 were approved by the Bioethics Committee of the Universidad Nacional Hermilio Valdizán, Huánuco, 377 Peru. The study was carried out in compliance with the ARRIVE guidelines.

378 SARS-CoV-2 (28549) virus used in the challenge was provided by the National Institute of Health (INS), 379 Lima, Peru, in accordance with relevant guidelines and regulations. The isolation of the SARS-CoV-2 380 virus was approved by the General Direction of the Public Health Centre of the INS.

\section{$381 \quad$ Animals}

382 One hundred male and female Golden Syrian hamsters (Mesocricetus auratus) aged 4-5 weeks were 383 obtained from the Peruvian National Institute of Health (INS). For the in-vivo assay, all hamsters were 384 transferred and acclimatized to the Animal Biosafety Level 3 (BSL-3) facility for 1 week. There, they 385 were vaccinated with NDV-vectored SARS-CoV-2 vaccine and later challenged with live SARS-CoV-2.

386 Development and characterization of recombinant NDV expressing SARS-CoV-2 RBD and S1 387 antigens

388 Cell Culture

389 African green monkey kidney cells, clone E6 (Vero E6, ATCC ${ }^{\circledR}$ CRL-1586 $^{\mathrm{TM}}$ ) and DF-1 cells 390 (derived from Chicken Fibroblast), were maintained in Dulbecco's modified Eagle's medium 391 (DMEM), supplemented with 5\% heat-inactivated fetal bovine serum (FBS) (HyClone ${ }^{\mathrm{TM}}$ GE Healthcare 392 Life Science, USA). Vero cells (Vero 81, ATCC ${ }^{\circledR}$ CCL-81 ${ }^{\mathrm{TM}}$ ) were grown in Eagle’s Minimum Essential 393 Medium (EMEM) supplemented with 10\% FBS, $100 \mathrm{IU} / \mathrm{mL}$ of penicillin, and $100 \mu \mathrm{g} / \mathrm{mL}$ streptomycin. 394 All cell lines were cultivated at $37^{\circ} \mathrm{C}$ in an atmosphere of $5 \% \mathrm{CO}_{2}$. 
396 Our vaccine candidates are based on the recombinant lentogenic NDV strain LaSota, which was

397 designated the rLS1 virus. The design and construction of a pFLC-LS1 plasmid (19,319 nucleotides (nt))

398 containing the full-length genome of an infectious NDV clone, and the three support plasmids containing

399 the N, P, and L genes (pCI-N, pCI-P, and pCI-L, respectively) have been previously described ${ }^{58}$. This

400 NDV-based system is protected under a Peruvian patent 001179-2014/DIN.

401 The genetic sequences of the RBD and the S1 subunit of the S protein correspond to the SARSCoV-2

402 strain isolate from China (GenBank accession no. MN908947.3). To improve the incorporation of RBD

403 and S1 into the NDV virion, we designed two cassettes. First, the HN-RBD transcriptional cassette

404 (1,013 nt) contained the genetic sequences of the RBD (636 nt), followed by complete transmembrane

405 domain (TM), and cytoplasmic tail (CT) of the NDV haemagglutinin- neuraminidase (HN) gene. Second,

406 the S1-F transcriptional cassette (2,441 nt), which contained the genetic sequence of the S1 subunit

407 (2,043 nt), taken from the S gene (3,822 nt). This sequence was fused with the TM and CT of the fusion

408 (F) gene. These TM and CT gene sequences of HN and F genes were obtained from the pFLC-LS1

409 plasmid. Both transcriptional cassettes were flanked with specific gene-end (GE) and gene-start (GS)

410 transcriptional signals of the paramyxovirus genome ${ }^{59}$. Further, these cassettes, flanked with restriction

411 sites of $B b v C I$, were chemically synthesized and were subsequently cloned into plasmid pUC57 by

412 GenScript (Piscataway, NJ, USA). These plasmids were purified and DNA extracted using QIAGEN

413 Plasmid Midi Kit (100), according to the manufacturer's instructions.

414 The pFLC-LS1 plasmid, containing a unique BbvCI site, was digested with $B b v C I$ enzyme to obtain the

415 linearized plasmid. Both the HN-RBD and S1-F transcriptional cassettes were digested with the same

416 enzyme and inserted into the P/M junction of the pFLC-LS1 to be expressed as a separate mRNA. The

417 resulting plasmids were designated as pFLC-LS1-HN-RBD (20,315 nt) and pFLCLS1-S1-F (21,743 nt).

\section{Recovery of the rLS1-HN-RBD and rLS1-S1-F virus}

419 Briefly, the rLS1-HN-RBD and rLS1-S1-F viruses were recovered by co-transfection with a fulllength 420 plasmid complementary DNA (cDNA) of each construct, pFLC-LS1-S1-F and pFLC-LS1HN-RBD, 421 respectively, together with three support plasmids, as described previously ${ }^{58}$. The recovered viruses were 422 injected into the allantoic cavities of 9 day old SPF embryonated chicken eggs (Charles River, Norwich, $423 \mathrm{CT}$, USA). After incubation for four days at $37^{\circ} \mathrm{C}$, the allantoic fluid containing the recovered virus were 424 harvested, clarified, aliquoted and stored at $-80^{\circ} \mathrm{C}$. The presence and recovery of viruses were confirmed 425 by hemagglutination (HA) assays using $1 \%$ chicken red blood cells. The identity of the recombinant 426 viruses was confirmed by reverse transcription-polymerase chain reaction (RT-PCR) and by Sanger 427 sequencing, as described before 
430 To examine the SARS-CoV-2 S RBD and S1 subunit proteins expression, Vero-E6 cells were infected 431 with the recombinant rLS1-HN-RBD, rLS1-S1-F and rLS1 viruses at a multiplicity of infection (MOI) of

432 0.5. After 48 hours post-infection (hpi), the cells were fixed with $4 \%$ paraformaldehyde for 25 minutes

433 ( $\mathrm{min}$ ), and then the monolayer was washed three times with Dulbecco's phosphate-buffered saline

434 (DPBS) and permeabilized with Triton 0.1\% X-100 for $15 \mathrm{~min}$ at room temperature (RT). After washing

435 with the cells with DPBS, the monolayer was incubated with the rabbit polyclonal antibody specific to

436 SARS-CoV-2 RBD protein (1:200) (Sino Biological, Beijing, China), and a chicken antiserum specific to

437 Newcastle disease virus (1:200)

438 (Charles River, Norwich, CT, USA) for $1.5 \mathrm{~h}$ at RT. Afterwards, the monolayer was incubated with

439 Donkey Anti-Rabbit IgG H\&L-Alexa Fluor ${ }^{\circledR} 594$ (1:250) and Goat Anti-Chicken IgY H\&L-Alexa

440 Fluor ${ }^{\circledR} 488$ (1:1000) (Abcam, Cambridge, MA, USA) for $60 \mathrm{~min}$ at RT. Finally, the cells were developed

441 with 4',6-diamidino-2-phenylindole (DAPI) for $5 \mathrm{~min}$ and observed using an ObserverA1 fluorescence

442 microscope (Carl Zeiss, Germany). Digital images were taken at $400 \mathrm{X}$ magnification and processed with

443 the AxioCam MRc5 camera (Carl Zeiss, Germany).

444 Western Blot Analysis

445 To evaluate the SARS-CoV-2 RBD and S1 subunit proteins expression, Vero E6 cells were infected with

446 the recombinant viruses mentioned above at an MOI of 1. At 48 hpi, the cells were harvested, lysed, and

447 analyzed by Western blot. Additionally, to verify the incorporation of the RBD and S1 subunit proteins

448 into rLS1-HN-RBD and rLS1-S1-F viruses, viral particles from allantoic fluid of SPF chicken

449 embryonated eggs infected with the recombinant viruses and rLS1, were concentrated by

450 ultracentrifugation (Ultracentrifuge, Beckman, Coulter) at 18,000 revolutions per minute (rpm) at $4^{\circ} \mathrm{C}$,

451 and partially purified on a $25 \%$ sucrose cushion. Western blot analysis was carried out using partially

452 purified viruses from allantoic fluid and lysate from infected cells, using a rabbit polyclonal antibody

453 specific to SARS-CoV-2 RBD protein (Sino Biological, Beijing, China) (2/5000) as the primary antibody

454 and anti-Rabbit IgG conjugated to HRP (GenScript, Piscataway, NJ, USA) (2/5000) as a secondary

455 antibody. The protein expression was visualized with a CCD camera Azure c600 imaging system (Azure

456 Biosystems, Dublin, USA).

457 Detection of RBD and S1 subunit proteins on the viral surface by flow cytometry

458 To determine the presence of RBD on the viral surface of rLS1-HN-RBD, and the presence of the 
459 S1 subunit on rLS1-S1-F viruses, virion particles were purified with a 25\% sucrose cushion. Vero E6

460 cells were harvested and washed with DPBS with 5\% FBS. Approximately, $1 \times 10^{6}$ cells were blocked

461 with DPBS with $5 \%$ of normal mouse serum for $30 \mathrm{~min}$ at $37^{\circ} \mathrm{C}$. Then, the cells were incubated with

$462 \mathrm{rLS} 1(0.36 \mathrm{mg} / \mathrm{mL}), \mathrm{rLS} 1-\mathrm{S} 1-\mathrm{F}(0.09 \mathrm{mg} / \mathrm{mL})$ or rLS1-HN-RBD $(0.2 \mathrm{mg} / \mathrm{mL})$ purified viruses for $30 \mathrm{~min}$

463 at $37^{\circ} \mathrm{C}$. To remove the residual viral particles not attached to Vero E6, the cells were washed with DPBS

464 and 5\% FBS twice. Subsequently, the mix was marked with rabbit monoclonal antibody anti-SARS-

465 CoV-2 S1 (1:200) (Sino Biological, Beijing, China) as primary antibody for $1 \mathrm{~h}$ at $37^{\circ} \mathrm{C}$, followed by goat

466 anti-rabbit IgG Alexa Fluor® 488 (1:200) (Abcam, Cambridge, MA, USA) as secondary antibody.

467 Finally, the cells were analyzed in FACS Canto II (BD Biosciences, USA) flow cytometer. The data

468 obtained were analyzed using the software FlowJo v.10.6 (BD Biosciences, USA), where the percentage

469 of positive cells was taken to indicate detection of the SARS-CoV-2 S1 subunit or RBD on the viral

470 surface of viruses bound to Vero E6.

471 Detection of RBD and S1 subunit genes by RT-PCR

472 For the detection of rLS1-HN-RBD and rLS1-S1-F recombinant virus, viral RNA was extracted from

473 allantoic fluid stocks using the QIAamp MinElute Virus Spin kit. Complementary cDNA was generated

474 from RNA using ProtoScript II cDNA Synthesis kit (New England Biolabs, USA), according to the

475 manufacturer's instructions. The cDNA was amplified using the high-fidelity

476 DNA polymerase Master Mix Q5 (New England Biolabs, USA), with the primers NDV-3LS1-

477 2020-F1 (5'-GATCATGTCACGCCCAATGC-3 ') and NDV-3LS1-2020-R1 (5'-

478 GCATCGCAGCGGAAAGTAAC-3') to amplify the complete inserts. The thermal cycling protocol

479 comprised an initial denaturation step at $98^{\circ} \mathrm{C}$ for 30 seconds (s), followed by 35 cycles of $98^{\circ} \mathrm{C}$ for $10 \mathrm{~s}$,

$48072^{\circ} \mathrm{C}$ for $20 \mathrm{~s}, 72^{\circ} \mathrm{C}$ for $30 \mathrm{~s}$ for the detection of rLS1-HN-RBD, and $40 \mathrm{~s}$ for the detection of rLS1-S1-F.

481 The final extension step was at $72^{\circ} \mathrm{C}$ for $2 \mathrm{~min}$.

482 Genetic stability of the rLS1-HN-RBD and rLS1-S1-F virus

483 The genetic stability of the recombinant viruses across multiples passages was evaluated on 9 day old

484 SPF embryonated chicken eggs, the viral RNA was extracted from purified viruses of the $3^{\text {rd }}$ and $6^{\text {th }}$

485 passage, and the presence of the gene inserts was confirmed by RT-PCR using specific primers. The

486 expression of the SARS-CoV-2 S1 subunit and RBD inserts was also evaluated using purified viruses

487 of the $3^{\text {rd }}$ and $6^{\text {th }}$ passage by Western blotting. 

pathogenicity

490 We compared the infectivity and growth properties between the rLS1-HN-RBD, rLS1-S1-F, and rLS1

491 viruses. The monolayer culture of DF-1 cells was seeded at 70\% confluence in 12- well plates and

492 infected with rLS1-HN-RBD, rLS1-S1-F, and rLS1 viruses at an MOI of 0.05. Cells were maintained

493 with DMEM containing $1 \% \mathrm{FBS}$ and $5 \%$ and incubated at $37^{\circ} \mathrm{C}$ with $5 \% \mathrm{CO}_{2}$. Supernatants of the

494 infected cells were collected at $12,24,36,48,60$, and 72 hpi and kept at $-80^{\circ} \mathrm{C}$. The titers of each

495 collected supernatant were determined using plaque assay, as described previously ${ }^{58}$. These experiments

496 were repeated at 3 specific time points. In addition, the morphology and size of the plaques of the two

497 recombinant viruses were compared with those formed with rLS1 infection. To determine the

498 pathogenicity, the viruses were evaluated by the Mean Death Time (MDT) and Intracerebral

499 Pathogenicity Index (IPIC) assays in 10 day old SPF embryonated chicken eggs and one day old SPF

500 chickens (Charles River Avian Vaccine Services, Norwich, CT, USA), respectively, using standard

501 procedures ${ }^{60}$.

502 Preparation and stability of the lyophilized vaccine

503 To check the stability of the lyophilized vaccine, the rLS1-RBD-HN and rLS1-S1-F viruses were 504 separately inoculated into the allantoic cavities of 9 to 11 day old SPF embryonated chicken eggs. After

505 four days of incubation at $37^{\circ} \mathrm{C}$, the allantoic fluids were harvested, clarified, and filtered using $0.22 \mu \mathrm{m}$

506 filters. The presence of the viruses in allantoic fluid was detected and confirmed by HA. Finally, the

507 allantoic fluid containing the rLS1-RBD-HN, rLS1-S1-F, and the mixture of both viruses were placed in

508 vials (2 mL/vial) and lyophilized using an MX5356 lyophilizer (Millrock Technology). The lyophilized

509 vaccine of the mixture of rLS1-HN-RBD and rLS1-S1-F viruses were stored at $4{ }^{\circ} \mathrm{C}$ and were evaluated

510 by plaque assay, HA, and Western blot assays on days 1, 30, and 50 after lyophilization. The lyophilized

511 vaccines were used in the following in vivo tests in hamsters.

\section{Immunogenicity in hamsters}

513 Forty-Eight Golden Syrian hamsters, weighing between 120-140 g, were divided into 4 groups (n

$514=12$ per group): group 1 (rLS1-HN-RBD), group 2 (rLS1-S1-F), group 3 (rLS1-HN-RBD/rLS1-S1F), and

515 the unvaccinated control group 4 , were intranasally immunized with $5 \times 10^{6} \mathrm{PFU} /$ hamster (40 $\mu \mathrm{L}$ volume)

516 following a prime-boost regimen with a two-week interval. Immunized hamsters were bled immediately

517 before the boost and fifteen days post-boost (at days 15 and 30 respectively), to measure the SARS-CoV-

5182 RBD and S specific serum IgG antibody by indirect ELISA assay, as well as the neutralizing antibody 
519 (nAbs) titers using a surrogate Virus Neutralization Test (sVNT) and by Plaque Reduction Neutralization 520 Test (PRNT) against SARS-CoV-2 virus.

521 Enzyme-Linked Immunosorbent Assay (ELISA) indirect IgG

522 Immunized hamsters were bled on days 15 and 30 of the immunization. All sera were isolated by 523 centrifugation at $2500 \mathrm{rpm}$ for $5 \mathrm{~min}$. To perform the assay, Nunc MaxiSorp 96-well flat-bottom plates 524 were coated with $100 \mu \mathrm{L}$ of SARS-CoV-2 RBD $(1 \mu \mathrm{g} / \mathrm{mL})$ and S1 subunit purified proteins (GenScript,

525 Piscataway, NJ, USA) dissolved in carbonate-bicarbonate buffer ( $\mathrm{pH} 9.6)$ and incubated at $4{ }^{\circ} \mathrm{C}$ 526 overnight. After coating the plates, standard ELISA protocol was followed as described earlier ${ }^{48}$.

527 Neutralization Tests using SARS-CoV-2 surrogate virus

528 Serum samples were processed to evaluate nAbs titers against SARS-CoV-2. All neutralization assays 529 performed with the surrogate Virus Neutralization Test (sVNT) (GenScript, Piscataway, NJ,

530 USA), following the manufacturer's instructions. The positive and negative cut-offs for SARS-

531 CoV-2 nAbs detection were interpreted as inhibition rate, as follows: positive, if $\geq 20 \%$

532 (neutralizing antibody detected), and negative, if <20\% (neutralizing antibody no detectable).

533 Plaque Reduction Neutralization Test (PRNT) of SARS-CoV-2 virus isolation of SARS-CoV-2 SARS-

534 CoV-2 (28549) was isolated from a nasopharyngeal swab sample collected from a patient with confirmed 535 SARS-CoV-2 infection in April 2020 in Lima, Peru. The identity of the virus was confirmed by whole 536 genome sequencing. Virus isolation was performed using Vero 81 cells maintained in Eagle's Minimum 537 Essential Medium (EMEM) supplemented with 10\% fetal bovine serum (FBS), $100 \mathrm{IU} / \mathrm{mL}$ of penicillin 538 and $100 \mu \mathrm{g} / \mathrm{mL}$ streptomycin and cultured at $37^{\circ} \mathrm{C}$ in an incubator with humidified atmosphere at $5 \%$ $539 \mathrm{CO}_{2}$. The sample was filtered through a $0.22 \mu \mathrm{m}$ pore membrane and inoculated with $100 \mu \mathrm{L}$ into a 540 confluent monolayer of Vero 81 cell line. Cells were observed daily to detect the appearance of any 541 cytopathic effect and virus was collected for confirmation. The virus was propagated in Vero 81 cell 542 culture for viral stock production at $-80^{\circ} \mathrm{C}$ and titer determined by PFU.

\section{Plaque Reduction Neutralization Test}

544 Pooled hamster serum samples were collected at day 30 of immunization and were heat-inactivated (HI) 545 at $56^{\circ} \mathrm{C}$ for $30 \mathrm{~min}$. Then after two-fold serial dilutions, serum samples were mixed and incubated with 546 40-50 PFUs of SARS-CoV-2 (28549) for $1 \mathrm{~h}$ at $37^{\circ} \mathrm{C}$ in $5 \% \mathrm{CO}_{2}$. These serumSARS-CoV-2 mixtures 547 were added to Vero E6 cells (in 24-well plates) and incubated at $37^{\circ} \mathrm{C}$ for $1 \mathrm{~h}$. After absorption, the 548 serum-virus mixtures were removed, and a liquid overlay medium (L-OM) comprising $0.75 \%$ 549 carboxymethylcellulose (CMC) (Sigma-Aldrich) supplemented with 2\% FBS was added to the 550 monolayer cells, which were incubated at $37^{\circ} \mathrm{C}$ for 5 days. The plates were fixed and stained with $10 \%$ 
551 formaldehyde and $0.5 \%$ crystal violet solution ${ }^{61}$. Each serum sample was tested in duplicate. The plates

552 were enumerated for the calculation of $\mathrm{PRNT}_{50}$, considered the gold standard method ${ }^{62}$.

553 Cellular immunity for Cytokines quantification by $q P C R$

554 Fifteen days post-immunization, spleens were collected from hamsters immunized with the different 555 recombinant viruses and stored in RNAlater reagent at $4^{\circ} \mathrm{C}$ overnight and then at $-80^{\circ} \mathrm{C}$. RNA was

556 extracted with RNeasy Mini kit, converted to cDNA with ProtoScript ${ }^{\circledR}$ II cDNA Synthesis kit, and stored 557 at $-20^{\circ} \mathrm{C}$ until analysis. Cytokines interferon-gamma (IFN $\gamma$ ), Tumor Necrosis Factor-Alpha (TNF- $\alpha$ ) and 558 interleukin-10 (IL-10), and reference gene $\beta$-actin were evaluated with primer pairs reported previously

$559 \quad{ }^{63-66}$. Standard curves were made for all primers, obtaining acceptable efficiency and $\mathrm{R}^{2}$ values (data not 560 shown). Master Mix preparation and cycling conditions were realized with Luna® Universal qPCR 561 Master Mix kit (New England Biolabs), according to manufacturer's instructions. Briefly, five $\mu \mathrm{L}$ of the 562 sample was used ( $2 \mathrm{ng} / \mu \mathrm{L}$ cDNA) with 2-3 technical replicas.

563 The qPCR experiments were done on the Rotor-Gene Q equipment (Qiagen, Hilden, Germany) and the $564 \Delta \Delta \mathrm{CT}$ method ${ }^{67}$ was used for data analysis.

565 Cellular immunity for Cytokines quantification by ELISA

566 Fifteen days post-immunization, whole blood obtained from hamsters immunized with rLS1-HN-

567 RBD, rLS1-S1-F, and rLS1-HN-RBD/rLS1-S1-F and allontoic fluid (mock) was centrifuged at $5681000 \mathrm{x}$ g for $20 \mathrm{~min}$ at $4^{\circ} \mathrm{C}$ to obtain the serum, which was duly aliquoted, frozen, and stored at $80^{\circ} \mathrm{C}$ 569 until analysis. For the quantitative ELISA, several kits for the accurate quantitative detection of hamster's 570 cytokines such as, TNF $\alpha$, IFN $\gamma$, IL-2, IL-4, and IL-10 were purchased from MyBioSource, Inc., San 571 Diego, CA. Cytokines quantifications were performed following the manufacturer's instructions. Briefly, 572 the sera were added in 96-well plates (in duplicate) which were pre-coated with antibodies against the 573 hamster's cytokines: TNF $\alpha$, IFN $\gamma$, IL-2, IL-4, and IL-10. The sera were incubated at $37^{\circ} \mathrm{C}$ and cytokines 574 revealed with the enzyme streptavidin or avidin conjugated with peroxidase (HRP), giving a color by 575 addition of the substrate 3, 3', 5, 5'tetramethylbenzidine (TMB). The plates were read in the EON 576 spectrophotometer (Biotek, USA) at

$577450 \mathrm{~nm}$. The level of cytokines $(\mathrm{pg} / \mathrm{mL})$ detected in the serum of the animals vaccinated with rLS1HN-

578 RBD, rLS1-S1-F, and rLS1-HN-RBD/rLS1-S1-F were compared with mock animals.

\section{Efficacy of the vaccines against SARS-CoV-2 challenge}

580 Forty-eight golden Syrian hamsters, divided into 4 groups $(n=12)$ : group 1 (rLS1-HN-RBD), group 2 581 (rLS1-S1-F), group 3 (rLS1-HN-RBD/rLS1-S1-F), and the unvaccinated control group 4, were 
intranasally challenged with $1 \times 10^{5}$ PFU/hamster in DMEM (40 $\mu \mathrm{L}$ volume) of SARS-CoV-2 at 45 days

583 post-prime immunization. Four animals in each group were anesthetized and sacrificed with one overdose

584 of $1 \mathrm{~mL}$ of a mixture of Ketamine (100 mg), Xylazine (20 mg), and Atropine Sulfate (1 mg) by

585 intramuscular injection at 2, 5, and 10 days post-challenge (dpc). The lung tissue samples (right and left

586 lobes) were separated into two parts: (1) The right lobe was used for the pathological examination, and

587 (2) the left lobe was immediately frozen at $-80^{\circ} \mathrm{C}$ until used; this lobe was used for live infectious virus

588 by viral isolation. SARS-CoV-2 (28549) virus used in the challenge was kindly provided by the National

589 Institute of Health (INS), Lima, Peru. All work and handling with SARS-CoV-2 were performed in a

590 BSL-3 laboratory following the biosafety guidelines of INS.

591 Histopathology analysis

592 Lungs obtained from sacrificed hamsters at days 2, 5, and 10 post-challenge with SARS-CoV-2 were

593 fixed in $10 \%$ buffered formalin for $48 \mathrm{~h}$. Organs were then reduced and placed in a container for $24 \mathrm{~h}$

594 with buffered formalin. The containers with the organs were processed in an automatic tissue processor

595 (Microm brand) conducting the following processes: dehydration, diaphanating, rinsing, and

596 impregnation within an $8 \mathrm{~h}$. Organs embedded in paraffin were cut to a thickness of 5 microns

597 (Microtome Leica RM2245 of disposable metal blades), placed in a flotation solution in a water bath and

598 then fixed on a slide sheet, and dried in the stove (at $37^{\circ} \mathrm{C}$ for 1 to $2 \mathrm{~h}$ ). The staining was done with the

599 Hematoxylin and Eosin staining method (H\&E) in a battery of staining bottles to remove paraffin,

600 hydration, hematoxylin coloration, washing, Eosin coloration, rinsing, dehydration, drying, rinsing, and

601 mounting in a microscope slide with Canada Balm (glue), and drying (at $37^{\circ} \mathrm{C}$ for 12 to $24 \mathrm{~h}$ ) for further

602 labeling. The final slides colored with H\&E were taken and analyzed under an AxioCam MRc5 camera

603 and AxioScope.A1 microscope (Carl Zeiss, Germany) at an amplitude of 20 and $40 \mathrm{x}$ by a board-certified

604 veterinary pathologist.

605 Viral viability: Culture and immunofluorescence assay (IFA)

606 For virus viability, 60 lung tissue samples from challenged animals were crushed and homogenized in 5

$607 \% \mathrm{w} / \mathrm{v}$ of DMEM $1 \%$ antibiotic, antimycotic and centrifuged at 10,000 rpm for $10 \mathrm{~min}$ at $4^{\circ} \mathrm{C}$. The

608 supernatant was filtered with a $0.22 \mu \mathrm{m}$ Millipore filter membrane, then $100 \mu \mathrm{L}$ inoculated into a

609 confluent monolayer of the Vero 81 cell line, and cultured at $37^{\circ} \mathrm{C}$ in an incubator with humidified

610 atmosphere at $5 \% \mathrm{CO}_{2}$. The cultures were observed daily for 10 days through the inverted microscope.

611 Lung virus isolation was confirmed by RT-PCR, as described previously ${ }^{68}$. The IFA was performed

612 using a polyclonal antibody against SARS-CoV-2 from convalescent patients of COVID-19 disease, and

613 anti-human IgG peroxidase conjugate (Sigma). 
615 To assess hamster's mobility (in groups 1 to 4) post-challenge, the average velocity, average acceleration,

616 and average displacement were calculated based on videos with a camera positioned on top of the

617 hamsters. The videos were analyzed on days 2, 5, and 10 post-challenge.

618 It should be noted that the conditions of video recording (distance and focus) were kept the same;

619 therefore, the pixels always reflect the same distance. Since hamsters do not necessarily move a lot at the

620 border of the box, we estimated average velocity, acceleration and displacement based on any movement

621 that took place away from the edges the box (Supplementary Figure 2). Movement along the edges of the

622 box were excluded and we tracked movement through a 2-3 min time period. After that, the hamsters

623 were tracked in those time intervals where the hamster has no interaction with the edge of the box.

624 Tracking was carried out using the Kernelized Correlation Filter (KCF) ${ }^{69}$. The implementation of this

625 tracking algorithm was developed using the OpenCV library and the

626 Python language. The result of tracking the hamsters was a record of the positions (X and $\mathrm{Y}$ ) of the

627 hamster in the image. Finally, once the tracking record was obtained at the intervals of interest, the

628 average velocity, average acceleration, and average displacement were calculated for each of the

629 hamsters.

\section{Animal weight variation}

631 The body weight change was measured on days 2, 5, and 10 post-challenge. An additional mock group

$632(n=12)$ of unvaccinated and unchallenged animals outside the BSL3 were evaluated. These measurements

633 were used to calculate the percentage of body weight variation, compared to day 0 for each animal.

\section{Statistical analysis}

636 For the statistical analysis of the weight variation in hamster groups, we used the one factor analysis of

637 variance (ANOVA) in the statistical package Stata software v.16. For the comparison of treatments of the 638 quantification of Cytokines, by qPCR and ELISA, we used the non-parametric

639 Mann-Whitney-Wilcoxon test. Both tests were performed using the statistical software STATA

640 v.16. To evaluate the statistical significance of body weight change in hamster groups, and a oneway

641 ANOVA with multiple comparisons for all the treatments involved was performed in the software

642 GraphPad Prism v.8.0.1. To evaluate changes in hamsters' mobility over time, nonparametric statistics

643 using the Mann-Whitney and Kruskal-Walls tests were used SciPy v1.5.2 package. In all analyses,

$644 \mathrm{P}<0.05 \%$ is considered statistically significant. To assess plaque reduction (\%) of neutralization from the

645 different groups of hamsters, we used two-way ANOVA and Tukey’s post hoc in software GraphPad

646 Prism v.8.0.1. 
648 FIGURE LEGENDS

650 Figure 1. The strategy used for the generation of the recombinant NDVs expressing SARS-CoV-2 RBD and S1. (A)

651 The schematic representation of the strategy of construction of the recombinant NDVs. Two transcriptional cassettes

652 were designed for expressing RBD and S1: 1) HN-RBD was fused with the complete transmembrane domain (TM)

653 and the cytoplasmic tail (CT) of the haemagglutinin-neuraminidase (HN) gene, 2) S1-F was fused with the TM/CT

654 of the fusion (F) gene from the full-length pFLC-LS1. (B) The full-length antigenome of NDV strain LaSota clone

655 (pFLC-LS1) was used as a backbone clone, the pFLC-LS1-HN-RBD and pFLC-LS1-S1-F were generated from

656 cassettes expressing RBD and S1 genes inserted into NDV genome under control of transcriptional gene end (GE)

657 and gene start (GS) signals. The names, position, and direction of the primers used are shown with arrows (blacks)

658 indicating the size products. $(\mathbf{C})$ The insertion of the expression cassette into the non-coding region between the P/M 659 genes of NDV genome was verified by RTPCR using the junction primers NDV-3LS1-2020-F1 and NDV-3LS1-

660 2020-R1, as shown in (B).

661 Figure 2. Expression of SARS-CoV-2 RBD and S1 proteins in infected Vero E6 cells and NDV particles. (A)

662 Western blot detection for the HN-RBD and S1-F proteins expression. Vero E6 cells were infected with the rLS1, 663 rLS1 rLS1-HN-RBD, and rLS1-S1-F viruses at an MOI of 1.0. After 48 hpi, the cells were lysed and analyzed by 664 western blotting. (B) To verify the incorporation of the HN-RBD and S1-F proteins into rLS1-HN-RBD, and rLS1-

665 S1-F viruses, the viral particles in allantoic fluid of infected SPF chicken embryonated eggs with the recombinant

666 viruses and rLS1, was concentrated by ultracentrifugation, and partially purified on a $25 \%$ sucrose cushion.

667 Western blot analysis was carried out using partially purified viruses and lysate from infected cells, using a rabbit

668 antibody specific to SARS-CoV-2 RBD protein and Anti Rabbit IgG conjugated to HRP. The black arrow indicates

669 the expected protein band. The gels are shown with equal running conditions. (C) Vero-E6 cells infected with the

$670 \mathrm{rLS1}$, rLS1-HN-RBD, and rLS1-S1-F at an MOI of 0.5. After $48 \mathrm{~h}$, the expression of RBD and S1 proteins was

671 detected by Immunofluorescence assay using a rabbit antibody specific to SARS-CoV-2 RBD protein, and a

672 Donkey Anti-Rabbit IgG H\&L-Alexa Fluor 594. Therefore, the NDV was detected using a chicken antiserum

673 specific to the NDV, and a Goat Anti-Chicken IgY H\&L-Alexa Fluor® 488. Cell nuclei were stained with DAPI. A

674 scale bar of 50- $\mu \mathrm{m}$. Image magnification 200x. (D) Detection of S1 or RBD proteins on the viral surface of rLS1-

675 S1-F and rLS1-HN-RBD viruses' attachment to Vero E6 cells was performed in two independent experiments. The

676 cells were incubated with purified viruses rLS1-HN-RBD or rLS1-S1-F, for $30 \mathrm{~min}$. Subsequently, the cells were

677 labeled with rabbit monoclonal antibody anti-SARSCOV-2 S1 as the primary antibody, followed by secondary

678 antibody goat anti-rabbit IgG Alexa Fluor 488.

679 The cells were then analyzed by a flow cytometer. The percentage of positive cells indicates the detection of

680 S1 or RBD proteins on the viral surface of viruses bound to Vero E6 and is shown in the dot plot for rLS1S1-F virus

681 and SLS1 -HN-RBD virus; including negative controls for each assay determined by cells incubated with phosphate-

682 buffered saline (PBS) or rLS1 virus. 
683 Figure 3. The intranasal vaccine elicits specific antibodies against RBD protein and neutralizing antibodies against 684 SARS-CoV-2 in hamsters. (A) Immunization regimen. To evaluate the immunogenicity of the NDV vaccines, five685 week-old female and male golden Syrian hamsters were used in this study. The hamsters were randomly divided 686 into five groups. The hamsters were vaccinated by intranasal route with live NDV vaccine, following a prime-boost687 regimen with a two-week interval. Group 1 received rLS1-HN-RBD $(n=12)$, Group 2 received the rLS1-S1-F $688(\mathrm{n}=12)$, Group 3 received the mixture of rLS1-HN-RBD/rLS1-S1-F ( $n=12)$, Group 4 did not receive any vaccine $689(\mathrm{n}=12)$ and served as a positive control group, and Group 5 receive no vaccine and was not challenged, hence 690 serving as a healthy control group $(n=12)$. One booster immunization with the same concentration of each vaccine 691 was applied in all vaccinated groups at the second week. (B) ELISA assay to measure SARS-CoV-2 RBD-specific 692 serum IgG antibody, and (C) S1 subunit-specific serum IgG antibody. Sera from hamsters at pre-boost and 15 days 693 after boost were evaluated. SARS-CoV-2 RBD purified recombinant protein was used for ELISA. The cutoff was 694 set at 0.06. (D). Immunized hamsters were bled preboost and 15 days after boost. All sera were isolated by low695 speed centrifugation. Serum samples were processed to evaluate the neutralizing antibody titers against SARS-CoV6962 RBD protein using the surrogate virus neutralization test (sVNT). The positive cut-off and negative cut-off for 697 SARS-CoV-2 neutralizing antibody detection were interpreted as the inhibition rate. The cut-off interpretation of 698 results: result positive $\geq 20 \%$ (neutralizing antibody detected), result negative $<20 \%$ (neutralizing antibody no 699 detectable). (E) Figure depicts titers of plaque reduction neutralization test (PRNT) of SARS-CoV-2 on Vero cells 700 with pooled serum from hamsters immunized with rLS1-S1-F, rLS1-HN-RBD, and the mixture of both. (F) Plaque 701 reduction (\%) curves using pooled serum from the different groups of hamsters. Two-way ANOVA and Tukey's 702 post hoc were performed. *: $\mathrm{P}<0.05 . * *: \mathrm{P}<0.01$. ***: $\mathrm{P}<0.001 . * * *: \mathrm{p}<0.0001$.

703 Figure 4. Cellular immunity. These figures show cytokines measured by quantitative ELISA (pg/ml) on hamster 704 serum immunized with rLS1-HN-RBD ( $\mathrm{n}=3$ ), rLS1-S1-F ( $\mathrm{n}=3$ for IFN $\gamma, \mathrm{n}=2$ for IL-2), rLS1-HNRBD/rLS1-S1-F $705(\mathrm{n}=3)$ and mock $(\mathrm{n}=2)$ at 15 DPV. (A) IL-2 and (B) IFN $\gamma$. ns: not significant; $\mathrm{P}<0.05$. Fold expression of cytokines 706 by $\Delta \triangle \mathrm{qPCR}$ from hamster spleens ( $\mathrm{n}=13$ ) vaccinated with rLS1-HN-RBD ( $\mathrm{n}=4), \mathrm{rLS1}-\mathrm{S} 1-\mathrm{F}(\mathrm{n}=4)$, rLS1-HN707 RBD/rLS1-S1-F (n=4), and mock $(\mathrm{n}=1)$. IFN $\gamma(\mathbf{C}), \mathrm{TNF} \alpha(\mathbf{D})$, and IL-10 (E), were evaluated at 15 DPV. Each 708 individual present 3 technical replicas for GOI and 2 technical replicas for HKG, a No-RT control was included. 709 Non-parametric Mann-Whitney-Wilcoxon test was used with Stata software v.16. P values of $<0.05$ were considered 710 significant. * $\mathrm{P}<0.05$, ** $\mathrm{P}<0.01$, *** $\mathrm{P}<0.001, * * * * \mathrm{P}<0.0001$. NS, not significant

711 Figure 5. Efficacy of live NDV vaccines against SARS-CoV-2 infection in hamsters. Golden Syrian hamsters 712 groups vaccinated with rLS1-S1-F, rLS1-HN-RBD, the mixture rLS1-S1-F/rLS1-HN-RBD, and negative control 713 (not immunized) were challenged 30 days after the boost with SARS-CoV-2; an unimmunized and unchallenged 714 group was also included (Mock). (A) Viral isolation (\%) was done from the lung of each hamster group (n=4) at 715 days 2, 5, and 10 post-challenge. Two-way ANOVA and Tukey's post hoc were performed. *: $\mathrm{P}<0.05$. **: $\mathrm{P}<$ 716 0.01. ***: P < 0.001. ****: P < 0.0001. (B) Detection by qRT-PCR of SARSCoV-2 in culture supernatant of Vero 717 cells, inoculated with immunized and challenged hamster lung homogenates. The data show a significant difference 718 in the $\mathrm{Ct}$ value $* \mathrm{P}<0.05$, ** $\mathrm{P}<0.01$, *** $\mathrm{P}<0.001$, **** $\mathrm{P}<0.0001$. NS, not significant. (C) Lung histopathology 
719 of each hamster group $(n=4)$ was euthanized at different days post-infection (DPI). Hemorrhagic and infiltrated

720 areas are indicated by a yellow and black arrow, respectively. Image amplitude: 20x. Scale-bar: $100 \mu \mathrm{m}$.

721 Figure 6. Body weight and mobility analysis of SARS-CoV-2 challenged golden Syrian hamsters. (A)

722 Changes in body weight (percent weight change compared to day 0) of hamsters inoculated with SARS-CoV2 and

723 Mock group, at days 2, 5, and 10 post-challenged. Mobility assessment results shown (B) average velocity, (C)

724 average acceleration, and (D) average displacement. Mean \pm s.d. are shown. Asterisks indicate that results were

725 statistically significant compared to the control group $(\mathrm{P}<0.05)$.

726

727 FUNDING

728 This study was funded by FARVET. The National Council of Science and Technology from Peru

729 (CONCYTEC-FONDECYT) supported FARVET in the construction of the BSL3 facility where the

730 challenge study in hamsters was performed.

\section{ACKNOWLEDGEMENTS}

732 We thank the National Institute of Health from Peru (INS) for providing the SARS-CoV-2 virus aliquots

733 and for their participation in the virus neutralization, viral load and viability tests. We are grateful for the

734 excellent technical assistance, fruitful discussions and selfless support to the development of the project

735 done by Dr. Paquita Garcia, Dr. Henri Bailon, MSc. Miryam Palomino, Lic. Maribel Huaringa, and BSc.

736 Pamela Ríos researchers of the Laboratory of Virology of the INS.

737 We acknowledge Dr. Maria Salas, for her advice in the toxicity study. We are grateful to Dr.

738 Daniela Kirwan, Dr. Valerie Paz-Soldan, Dr. Gabriela Salmon, and doctoral candidate David Requena for

739 their comments and criticisms to the manuscript.

740 PATENT

741 Peruvian patent \# N33-2021/DIN has been filed for the vaccine candidates presented in

742 this study.

\section{COMPETING INTERESTS}

744 The authors declare no competing interests. 


\section{REFERENCES}

747 1. Gallagher, T. M. \& Buchmeier, M. J. Coronavirus spike proteins in viral entry and pathogenesis. $748 \quad$ Virology 279, 371-374 (2001).

749 2. Gorbalenya, A. E. et al. The species Severe acute respiratory syndrome-related coronavirus:

750 classifying 2019-nCoV and naming it SARS-CoV-2. Nat. Microbiol. 5, 536-544 (2020).

751 3. Walls, A. C. et al. Structure, function, and antigenicity of the SARS-CoV-2 spike glycoprotein.

$752 \quad$ Cell 181, 281-292.e6 (2020).

753 4. Huang, J. et al. Priming with SARS CoV S DNA and boosting with SARS CoV S epitopes

754 specific for CD4+ and CD8+ T cells promote cellular immune responses. Vaccine 25, 6981- 6991 755 (2007).

756 5. Yu, M. et al. Determination and application of immunodominant regions of SARS coronavirus 757 spike and nucleocapsid proteins recognized by sera from different animal species. J. Immunol. $758 \quad$ Methods 331, 1-12 (2008).

759 6. Du, L. et al. The spike protein of SARS-CoV - A target for vaccine and therapeutic development. $760 \quad$ Nat. Rev. Microbiol. 7, 226-236 (2009).

761 7. Ma, C. et al. Searching for an ideal vaccine candidate among different MERS coronavirus 762 receptor-binding fragments-the importance of immunofocusing in subunit vaccine design. 763 Vaccine 32, 6170-6176 (2014).

764 8. Ahmed, S. F., Quadeer, A. A. \& McKay, M. R. Preliminary identification of potential vaccine targets for the COVID-19 coronavirus (SARS-CoV-2) based on SARS-CoV immunological studies. Viruses 12, (2020).

767 9. Requena, D., Médico, A., Chacón, R. D., Ramírez, M. \& Marín-Sánchez, O. Identification of 768 novel candidate epitopes on SARS-CoV-2 proteins for South America: A review of HLA 769 frequencies by country. Front. Immunol. 11, 1-16 (2020).

770 10. Dai, L. \& Gao, G. F. Viral targets for vaccines against COVID-19. Nat. Rev. Immunol. 21, 73-82 $771 \quad$ (2021).

772 11. Guruprasad, L. Human SARS CoV-2 spike protein mutations. Proteins Struct. Funct. 773 Bioinforma. 1-8 (2021) doi:10.1002/prot.26042. 
774 12. Zhang, L. et al. SARS-CoV-2 spike-protein D614G mutation increases virion spike density and 775 infectivity. Nat. Commun. 11, 1-9 (2020).

776 13. Greaney, A. J. et al. Complete mapping of mutations to the SARS-CoV-2 spike receptorbinding domain that escape antibody recognition. Cell Host Microbe 29, 44-57.e9 (2021).

778 14. Van Egeren, D. et al. Risk of evolutionary escape from neutralizing antibodies targeting SARSCoV-2 spike protein. medRxiv (2020) doi:10.1101/2020.11.17.20233726.

15. Ou, X. et al. Characterization of spike glycoprotein of SARS-CoV-2 on virus entry and its immune cross-reactivity with SARS-CoV. Nat. Commun. 11, (2020).

16. Garcia-Beltran, W. F. et al. Multiple SARS-CoV-2 variants escape neutralization by vaccineinduced humoral immunity. Cell, (2021) doi:10.1016/j.cell.2021.03.013.

17. Zhou, D. et al. "Evidence of escape of SARS-CoV-2 variant B.1.351 from natural and vaccine-

18. World Health Organization. Covid-19 Situation report. World Health Organ. 31, 61-66 (2020).

787 19. Buschmann, M. D. et al. Nanomaterial delivery systems for mRNA vaccines. Vaccines 9, 1- 30 (2021).

20. Dong, Y. et al. A systematic review of SARS-CoV-2 vaccine candidates. Signal Transduct.

791 21. Amanat, F. \& Krammer, F. SARS-CoV-2 Vaccines: Status report. Immunity 52, 583-589 (2020).

792 22. Bashir Bello, M. et al. Exploring the prospects of engineered Newcastle disease virus in modern vaccinology. Viruses 12, 1-23 (2020).

794 23. Kim, S. H. \& Samal, S. K. Newcastle disease virus as a vaccine vector for development of human 795 and veterinary vaccines. Viruses $\mathbf{8},(2016)$.

796 24. Abozeid, H. H. et al. Development of a recombinant Newcastle disease virus-vectored vaccine for 797 infectious bronchitis virus variant strains circulating in Egypt. Vet. Res. 50, 1-13 (2019).

798 25. ICTV. International committee on taxonomy of viruses. https://talk.ictvonline.org/taxonomy/ 799 (2019).

800 26. Diel, D. G. et al. Complete genome and clinicopathological characterization of a virulent 801 Newcastle disease virus isolate from South America. J. Clin. Microbiol. 50, 378-387 (2012). 
802 27. Miller, P. J. \& Koch, G. Newcastle disease. In: Swayne, D.E., Glisson, J.R., McDougald, L.R.,

803 Nolan, L.K., Suarez, D.L., Nair, V. Diseases of Poultry (2013). doi:10.1016/B978-012-804607-

$804 \quad 4.00020-4$.

805 28. Bukreyev A., Collins P.L. Newcastle disease virus as a vaccine vector for humans. Curr Opin Mol $806 \quad$ Ther. 10, 46-55 (2008).

807 29. Freeman, A. I. et al. Phase I/II trial of intravenous NDV-HUJ oncolytic virus in recurrent 808 glioblastoma multiforme. Mol. Ther. 13, 221-228 (2006).

809 30. Schirrmacher, V. Cancer vaccines and oncolytic viruses exert profoundly lower side effects in 810 cancer patients than other systemic therapies: A comparative analysis. Biomedicines $\mathbf{8},(2020)$.

811 31. Burman, B., Pesci, G. \& Zamarin, D. Newcastle disease virus at the forefront of cancer 812 immunotherapy. Cancers (Basel). 12, 1-15 (2020).

813 32. Duan, Z., Xu, H., Ji, X. \& Zhao, J. Recombinant Newcastle disease virus-vectored vaccines 814 against human and animal infectious diseases. Future Microbiol. 10, 1307-1323 (2015).

815 33. Shirvani, E., Paldurai, A., Manoharan, V. K., Varghese, B. P. \& Samal, S. K. A recombinant 816 Newcastle disease virus (NDV) expressing S protein of infectious bronchitis virus (IBV) protects 817 chickens against IBV and NDV. Sci. Rep. 8, 1-14 (2018).

818 34. Saikia, D. P. et al. Recombinant Newcastle disease virus (NDV) expressing Sigma C protein of 819 avian reovirus (ARV) protects against both ARV and NDV in chickens. Pathogens 8, 145 (2019).

820 35. DiNapoli, J. M. et al. Newcastle disease virus, a host range-restricted virus, as a vaccine vector for intranasal immunization against emerging pathogens. Proc. Natl. Acad. Sci. U. S. A. 104, 97889793 (2007).

823 36. Liu, R. Q. et al. Newcastle disease virus-based MERS-CoV candidate vaccine elicits highlevel 824 and lasting neutralizing antibodies in Bactrian camels. J. Integr. Agric. 16, 2264-2273 (2017).

825 37. Sun, W. et al. A Newcastle disease virus (NDV) expressing a membrane-anchored spike as a costeffective inactivated SARS-CoV-2 vaccine. Vaccines 8, 1-14 (2020).

827 38. Sun, W. et al. Newcastle disease virus (NDV) expressing the spike protein of SARS-CoV-2 as a 828

829 39. Xiaojie, S., Yu, L., lei, Y., Guang, Y. \& Min, Q. Neutralizing antibodies targeting SARSCoV-2 $830 \quad$ spike protein. Stem Cell Res. 50, (2021). 
831 40. Gavor, E., Choong, Y. K., Er, S. Y., Sivaraman, H. \& Sivaraman, J. Structural basis of SARS-

832 CoV-2 and SARS-CoV antibody interactions. Trends Immunol. 41, 1006-1022 (2020).

833 41. Zhang, H. et al. Identification of an antigenic determinant on the S2 domain of the severe acute 834 respiratory syndrome coronavirus spike glycoprotein capable of inducing neutralizing antibodies.

$835 \quad$ J. Virol. 78, 6938-6945 (2004).

836 42. Imai, M. et al. Syrian hamsters as a small animal model for SARS-CoV-2 infection and 837 countermeasure development. Proc. Natl. Acad. Sci. U. S. A. 117, 16587-16595 (2020).

838 43. Sia, S. F. et al. Pathogenesis and transmission of SARS-CoV-2 in golden hamsters. Nature 583, $839 \quad 834-838(2020)$.

840 44. Park, J.-G. et al. Immunogenicity and protective efficacy of an intranasal live-attenuated vaccine

45. Bukreyev, A. et al. Recombinant Newcastle disease virus expressing a foreign viral antigen is attenuated and highly immunogenic in primates. J. Virol. 79, 13275-13284 (2005).

844 46. Nelson, C. B., Pomeroy, B. S., Schrall, K., Park, W. E. \& Linderman, R. J. An outbreak of conjunctivitis due to Newcastle disease virus (NDV) occurring in poultry workers. Am. J. Public Health Nations. Health 42, 672-678 (1952).

47. Lam, H. Y. et al. Corrigendum to 'safety and clinical usage of Newcastle disease virus in cancer

48. Izquierdo-Lara, R., Chumbe, A., Calderón, K., Fernández-Díaz, M. \& Vakharia, V. N. Genotypematched Newcastle disease virus vaccine confers improved protection against genotype XII challenge: The importance of cytoplasmic tails in viral replication and vaccine design. PLoS One

853 49. Zhao, W. et al. Newcastle disease virus (NDV) recombinants expressing infectious laryngotracheitis virus (ILTV) glycoproteins $\mathrm{gB}$ and $\mathrm{gD}$ protect chickens against ILTV and NDV challenges. J. Virol. 88, 8397-8406 (2014). 
859 51. Ma, J. et al. Newcastle disease virus-based H5 influenza vaccine protects chickens from lethal 860 challenge with a highly pathogenic H5N2 avian influenza virus. npj Vaccines 2, 1-10 (2017).

861 52. Dimitrov, K. M., Afonso, C. L., Yu, Q. \& Miller, P. J. Newcastle disease vaccines—a solved 862 problem or a continuous challenge? Vet. Microbiol. 206, 126-136 (2017).

863 53. Cardenas-Garcia, S. et al. Molecular epidemiology of Newcastle disease in Mexico and the potential spillover of viruses from poultry into wild bird species. Appl. Environ. Microbiol. 79, 4985-4992 (2013).

54. Cornax, I., Miller, P. J. \& Afonso, C. L. Characterization of live LaSota vaccine straininduced

55. Boumart, Z. et al. Thermal stability study of five Newcastle disease attenuated vaccine strains. Avian Dis. 60, 779-783 (2016).

56. Torjesen, I. Covid-19 will become endemic but with decreased potency over time, scientists believe. BMJ 18-19 (2021) doi:10.1136/bmj.n494.

873 57. Alexandra B Hogan et al. Report 33 - Modelling the allocation and impact of a COVID-19

58. Chumbe, A., Izquierdo-Lara, R., Calderón, K., Fernández-Díaz, M. \& Vakharia, V. N.

Development of a novel Newcastle disease virus (NDV) neutralization test based on recombinant NDV expressing enhanced green fluorescent protein. Virol. J. 14, 1-11 (2017).

59. Peeters, B. P. H., Gruijthuijsen, Y. K., De Leeuw, O. S. \& Gielkens, A. L. J. Genome replication

60. World Organization for Animal Health. OIE Manual of diagnostic tests and vaccines for terrestrial animals (mammals, birds and bees). OIE Manual of Diagnostic Test and Vaccines for

61. Mendoza, E. J., Manguiat, K., Wood, H. \& Drebot, M. Two Detailed Plaque Assay Protocols for the Quantification of Infectious SARS-CoV-2. Curr. Protoc. Microbiol. 57, 1- 15 (2020). the detection of neutralizing antibodies to four serotypes of dengue virus used in support of dengue vaccine development. Am. J. Trop. Med. Hyg. 88, 962-970 (2013). 
63. Boudewijns, R. et al. STAT2 signaling restricts viral dissemination but drives severe pneumonia in SARS-CoV-2 infected hamsters. Nat. Commun. 11, 1-10 (2020).

64. Chan, J. F., Zhang, A. J., Yuan, S. \& Kwok-Y, Y. Simulation of the clinical and pathological manifestations of Coronavirus Disease 2019 (COVID-19) in golden Syrian hamster model:

65. Ribeiro-Romão, R. P., Saavedra, A. F., Da-Cruz, A. M., Pinto, E. F. \& Moreira, O. C. Development of real-time PCR assays for evaluation of immune response and parasite load in golden hamster (Mesocricetus auratus) infected by Leishmania (Viannia) braziliensis.

66. Espitia, C. M. et al. Duplex real-time reverse transcriptase PCR to determine cytokine mRNA expression in a hamster model of New World cutaneous leishmaniasis. BMC Immunol. 11, (2010).

67. Livak, K. J. \& Schmittgen, T. D. Analysis of relative gene expression data using real-time quantitative PCR and the 2- $\Delta \Delta$ CT method. Methods 25, 402-408 (2001).

68. Padilla-Rojas C, Lope-Pari P, Vega- Chozo K, Balbuena-Torres J, Caceres-Rey O, novel coronavirus (SARS-CoV-2) strain causing a COVID-19 case in Peru. Microbiol Resour Announc 9e00303-20 9, 1-3 (2020). 


\section{Members of the COVID-19 Working Group in Perú:}

918 Katherine Calderon ${ }^{1,4}$, Aldo Rojas-Neyra ${ }^{1,4}$, Angela Montalvan ${ }^{1}$, Dora Rios-Matos ${ }^{1}$, Astrid Poma-

919 Acevedo ${ }^{1}$, Ricardo Choque-Guevara ${ }^{1}$, Kathy Pauyac ${ }^{1}$, Norma Perez-Martinez ${ }^{1}$, Manuel CriolloOrozco ${ }^{1}$,

920 Elmer Delgado-Ccancce ${ }^{1}$, Yacory Sernaque-Aguilar ${ }^{1}$, Doris Villanueva-Pérez ${ }^{1}$, Freddy

921 Ygnacio-Aguirre ${ }^{1}$, Ricardo Montesinos-Millan ${ }^{1}$, Naer Chipana-Flores ${ }^{1}$, Edison HuaccachiGonzalez ${ }^{1}$,

922 Pedro Huerta-Roque ${ }^{1}$, Gisela Isasi-Rivas ${ }^{1}$, Kristel Gutiérrez ${ }^{1}$, Andres Agurto-Arteaga ${ }^{1}$,

923 Abraham Licla-Inca ${ }^{1}$, Yudith Cauna-Orocollo ${ }^{1}$, Maria de Grecia Cauti-Mendoza ${ }^{1}$, Ricardo

924 Antiparra ${ }^{1}$, Manuel Ardiles-Reyes ${ }^{1}$, Xiomara Chunga-Girón ${ }^{1}$, Lewis De La Cruz ${ }^{1}$, Nicolás E. Delgado-

925 Pease $^{1}$, Christian Elugo-Guevara ${ }^{1}$, Oscar Heredia-Almeyda ${ }^{1}$, Gabriel Jiménez-Avalos ${ }^{1}$, Romina A.

926 Juscamaita-Bartra ${ }^{1}$, Dennis Núñez-Fernández ${ }^{1}$, Adiana Ochoa-Ortiz ${ }^{1}$, Gustavo E.

927 Olivos-Ramirez ${ }^{1}$, Erika Páucar-Montoro ${ }^{1}$, Jose L. Perez-Martinez ${ }^{1}$, Stefany Quiñones-Garcia ${ }^{1}$,

928 Ingrid Ramirez-Ortiz ${ }^{1}$, Daniel Ramos-Sono ${ }^{1}$, Angela A. Rios-Angulo ${ }^{1}$, Yomara K. Romero ${ }^{1}$, Mario I.

929 Salguedo-Bohorquez ${ }^{1}$, Luis F. Soto ${ }^{1}$, Luis Tataje-Lavanda ${ }^{1}$, Katherine Vallejos-Sánchez ${ }^{1}$, A.

930 Paula Vargas-Ruiz ${ }^{1}$, Renzo G. Villena ${ }^{1}$, Patricia Sheen ${ }^{1}$, Julio Ticona ${ }^{1}$, Manolo FernándezSanchez ${ }^{1}$,

931 Vikram N. Vakharia ${ }^{2}$, Eliana Icochea ${ }^{1,3}$, Luis Guevara-Sarmiento ${ }^{1}$, Mirko Zimic ${ }^{1}$, Manolo Fernández-

932 Díaz ${ }^{1}$

933 AFILITIONS

$934{ }^{1}$ Farmacológicos Veterinarios S.A.C. FARVET

$935{ }^{2}$ Institute of Marine and Environmental Technology, University of Maryland Baltimore County,

936 Baltimore, USA

937

$938{ }^{3}$ Laboratorio de Patología Aviar. Facultad de Medicina Veterinaria. Universidad Nacional Mayor de San

939 Marcos, Lima, Perú

$940 \quad{ }^{4}$ Universidad Nacional San Luis Gonzaga, Ica, Perú

\section{AUTHOR CONTRIBUTION STATEMENT}

944 MFD, MZ, and LGS, conceived the study and experiments. KC and ARN produced the NdV vaccine.

945 MFD, MZ, LGS, KC, ARN, APA, KVS, YCO, SQG and CWGP developed the protocols. KC, ARN,

946 APA, AM, IR, DRM, AAA, MGCM, GIR, KGM, NPM, YSA, FYA, DVP, RCG, RMM, IRO, JT, MFS

947 and GIR carried out the experiments. MSB, DNF, LTL, CWGP and MZ planned and carried out the

948 simulations. DNF and MSB analyzed the videos for mobility evaluation. MCO, EHG, EDC and KPA 
949 contributed to sample preparation. MZ, MFD, KC, ARN, VV, APA, DRM, EI and LGS analyzed and 950 interpreted the results. MFD, MZ, LGS, KC, ARN, VV, SQG, ARA, KVS and YCO took the lead in 951 writing the manuscript. MFD funded the study. All authors provided critical feedback and helped shape 952 the research, analysis and manuscript.

953

954 ADDITIONAL INFORMATION

955 Supplementary material accompanies this paper.

956

957 DATA AVAILABILITY

958 All relevant data are contained within the manuscript and the supplementary material. Additional raw 959 data will be available upon request.

960

961

962

963

964

965

966

967

968

969

$970 \quad$ FIGURES

971 Figure 1

972 

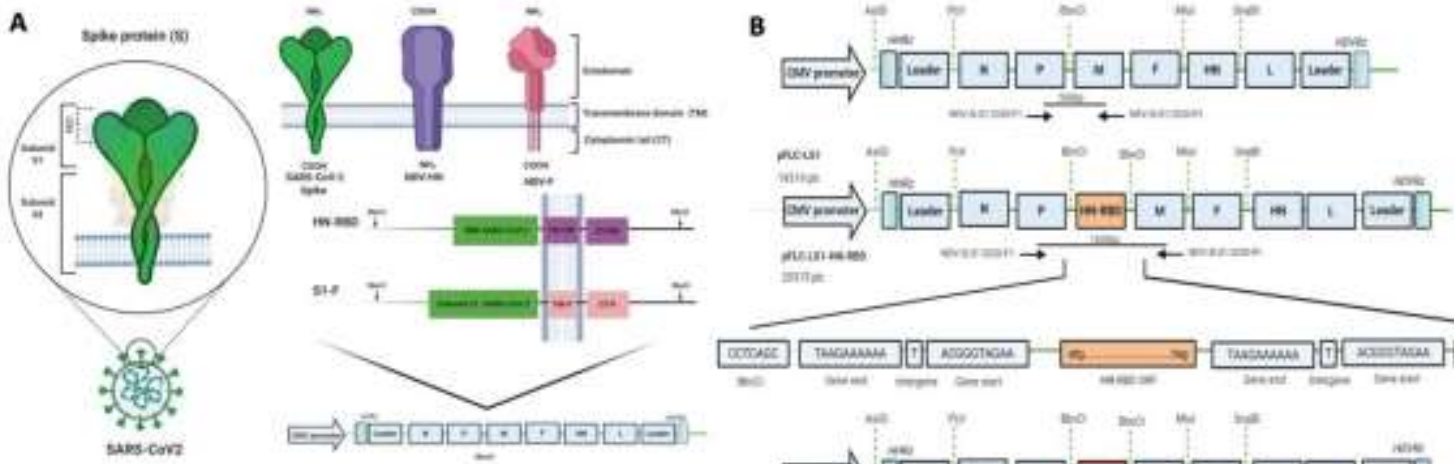

numinas

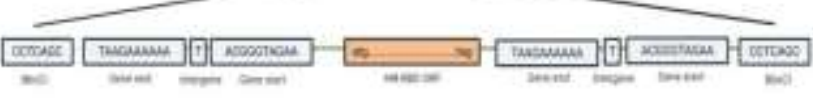

c

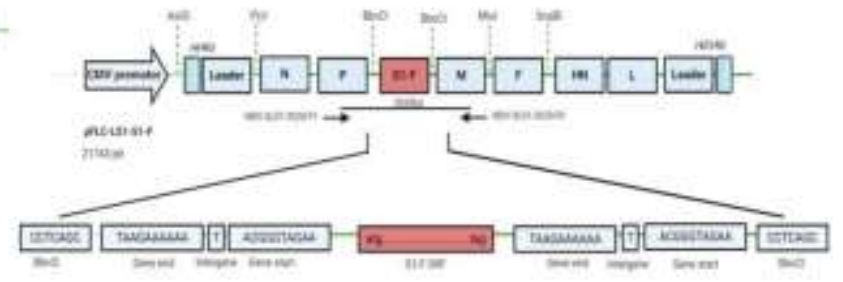

973

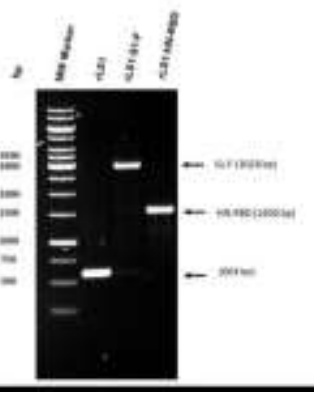

974

975

976

977

978

979

980

981

982

983

984

985 
Figure 2

A

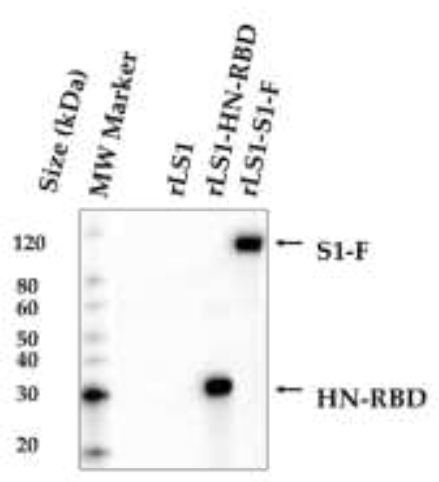

B
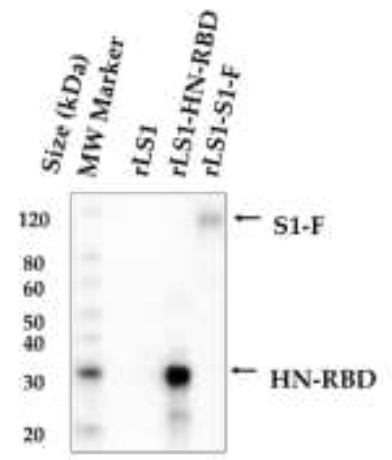

987

988 Figure 3

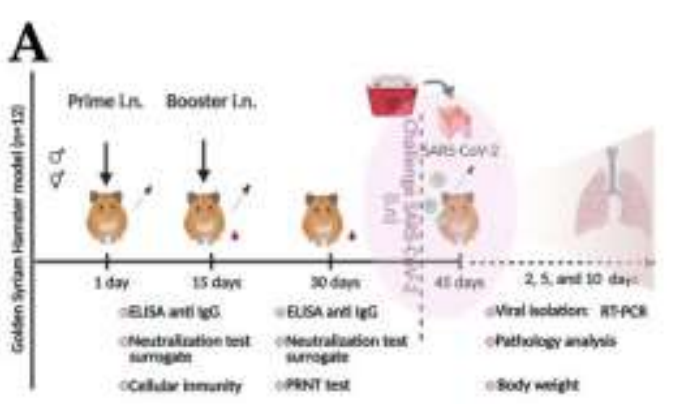

D

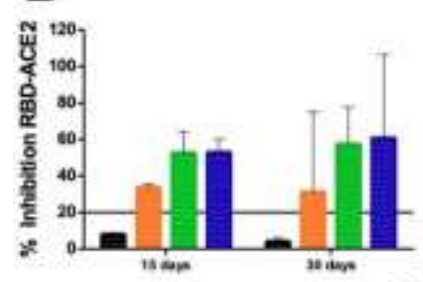

E

Days post-vaccination

ILS1-S1-F/rLS1-HN-RBD

- Negative control

rLS1-H1-FBD/rLS1-S1-F

Negative control

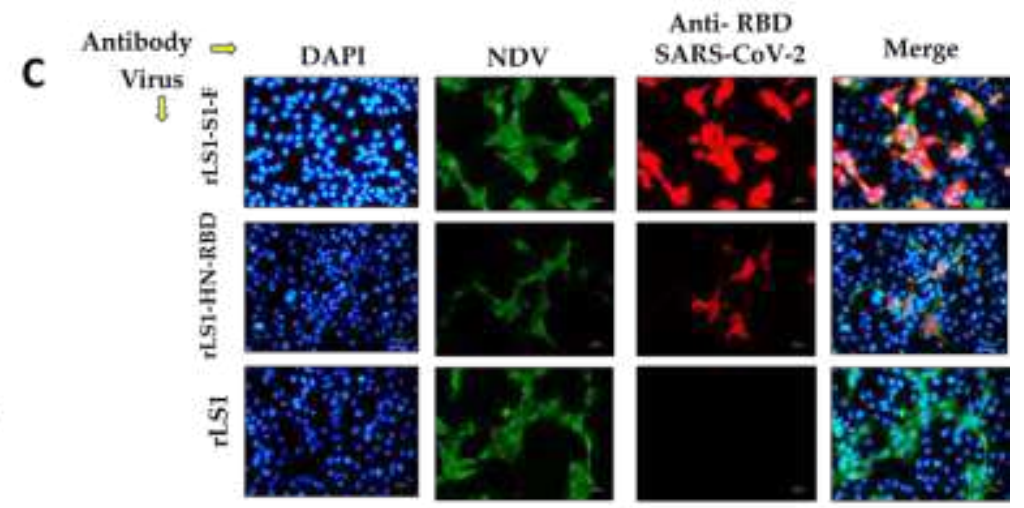

D
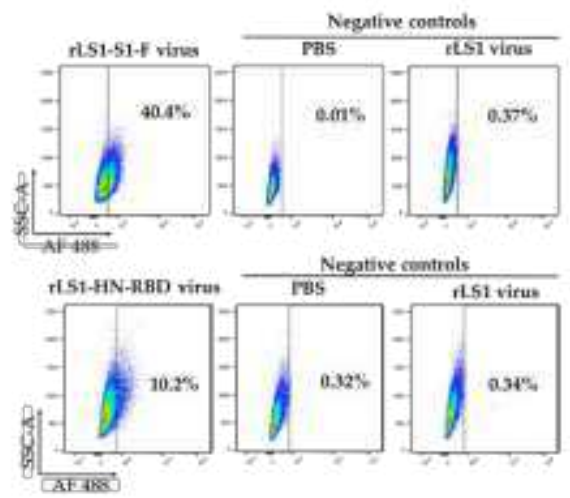

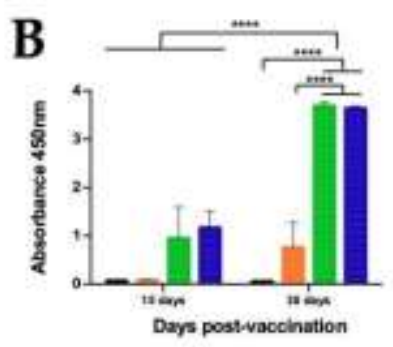

- Negathe control

WS1 HN-Red / ILS1-S1-F

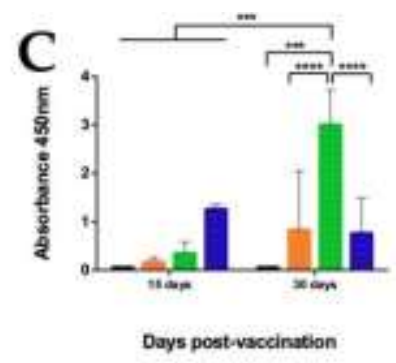

- Negative control

a tS1-Fi-RBD/RS1-S1-F

F

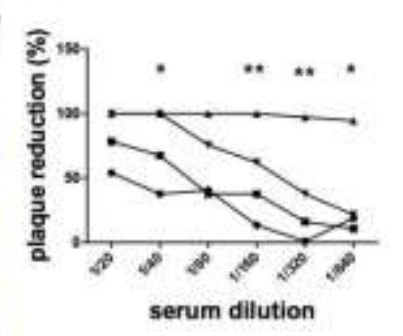

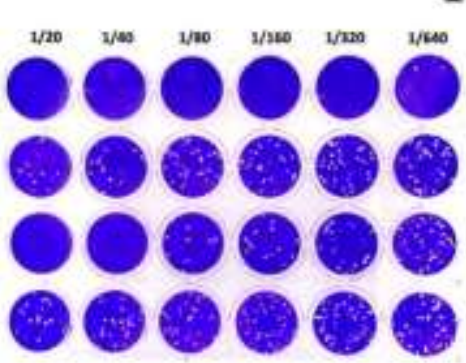

- rLS1-S1-FirLS1-HN-RBO

nsi-si-f

- negative control 
989

990

991

992

993

994

995

996

997

998

999

1000

1001 
Figure 4

1003

1004

1005

1006

1007

1008

1009

1010

1011

1012

1013

1014
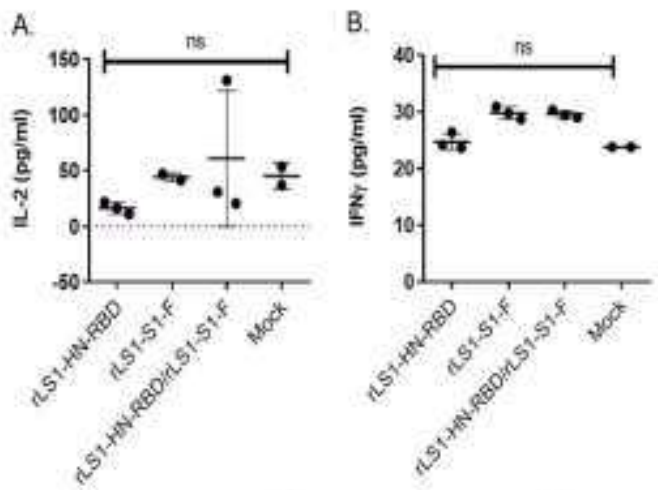

C
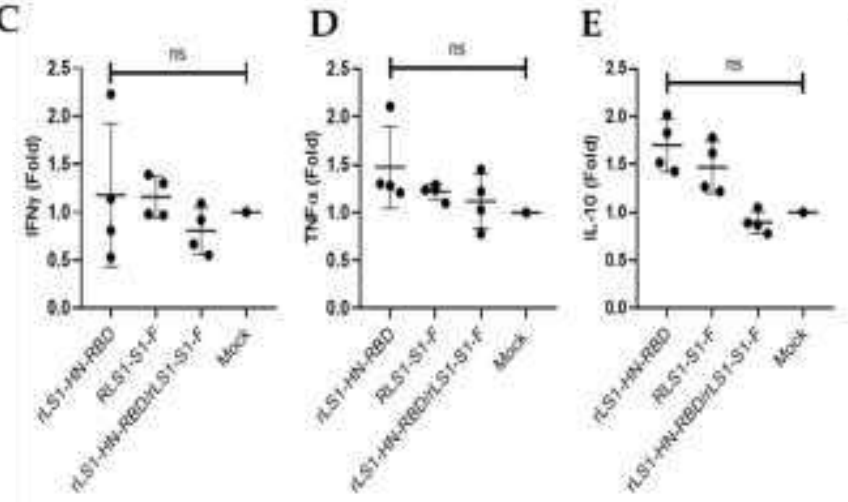

1015

1016

1017

1018

1019

1020

1021

1022

1023

1024

1025

1026 
102096 Figure 5

1028

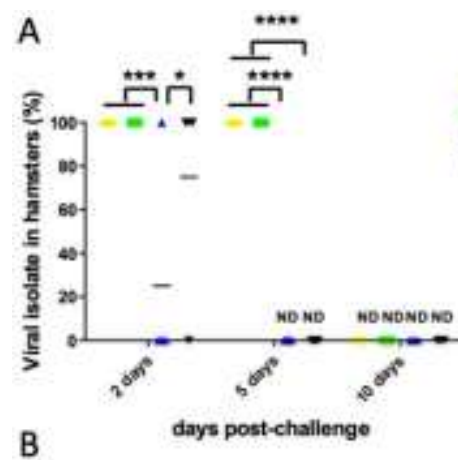

Control

- rLS1-HN-RBD

- rLS1-S1-F

- rLS1-S1-F/rLS1-HN-RBD

C

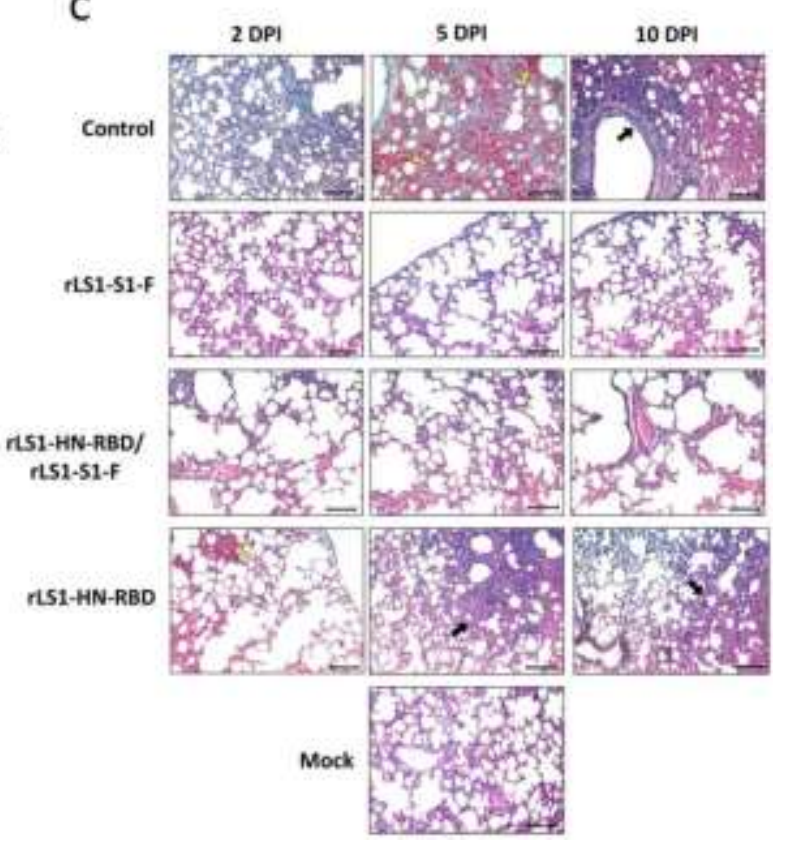

1029

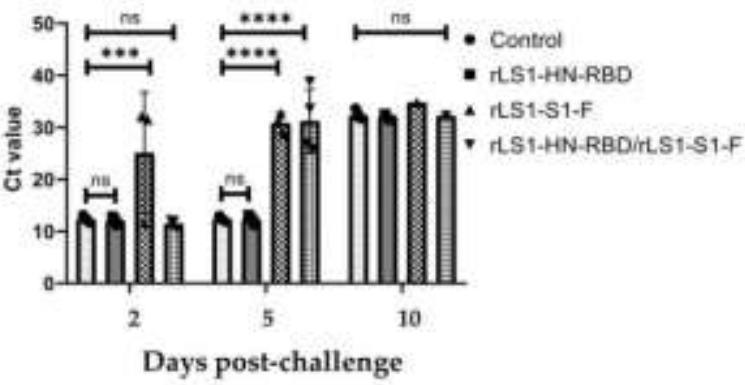

1-HN-RBD

1030

1031

1032

1033

1034

1035

1036

1037

1038

1039

1040

1041 
1043 Figure 6

1044

1045

A

B Average speed

1046

1047

1048
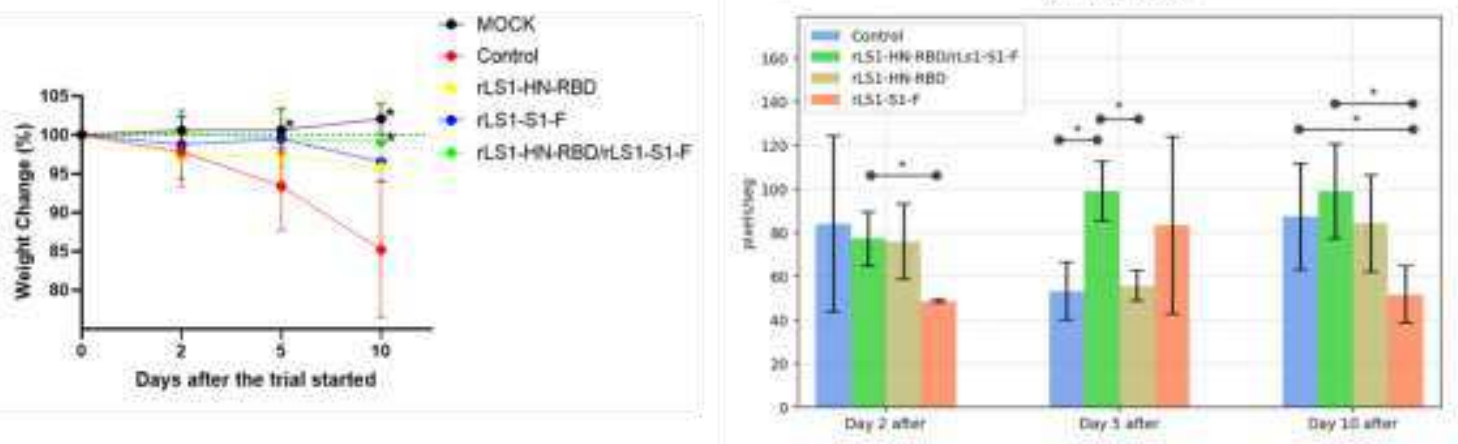

1050

1051
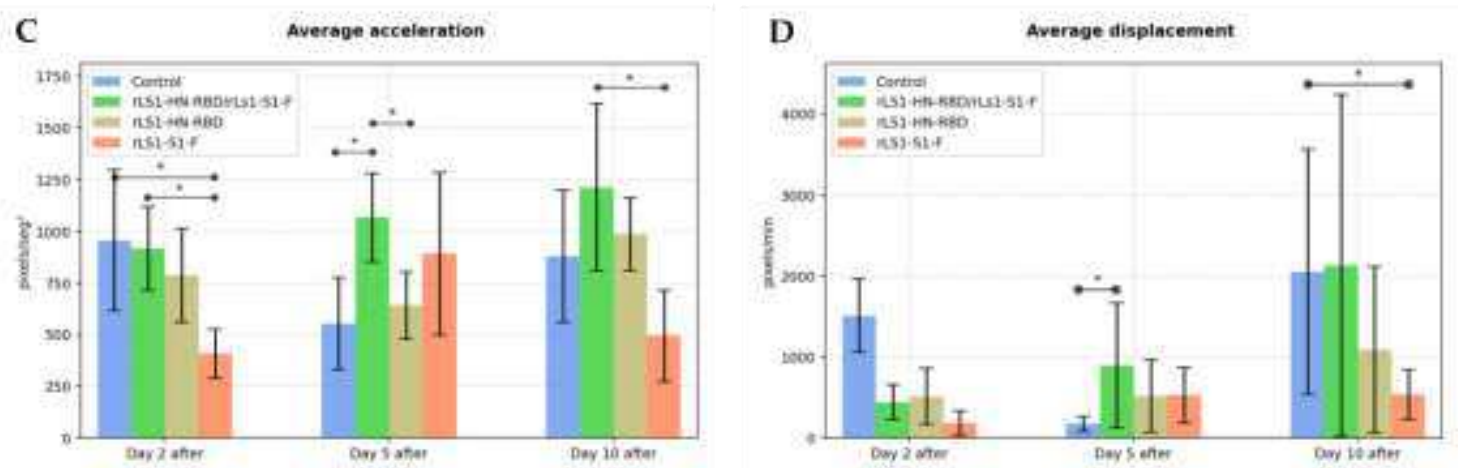
1053

1054

1055

1056

1057

1058

1059

1060

1061

1062

1063 
Figures

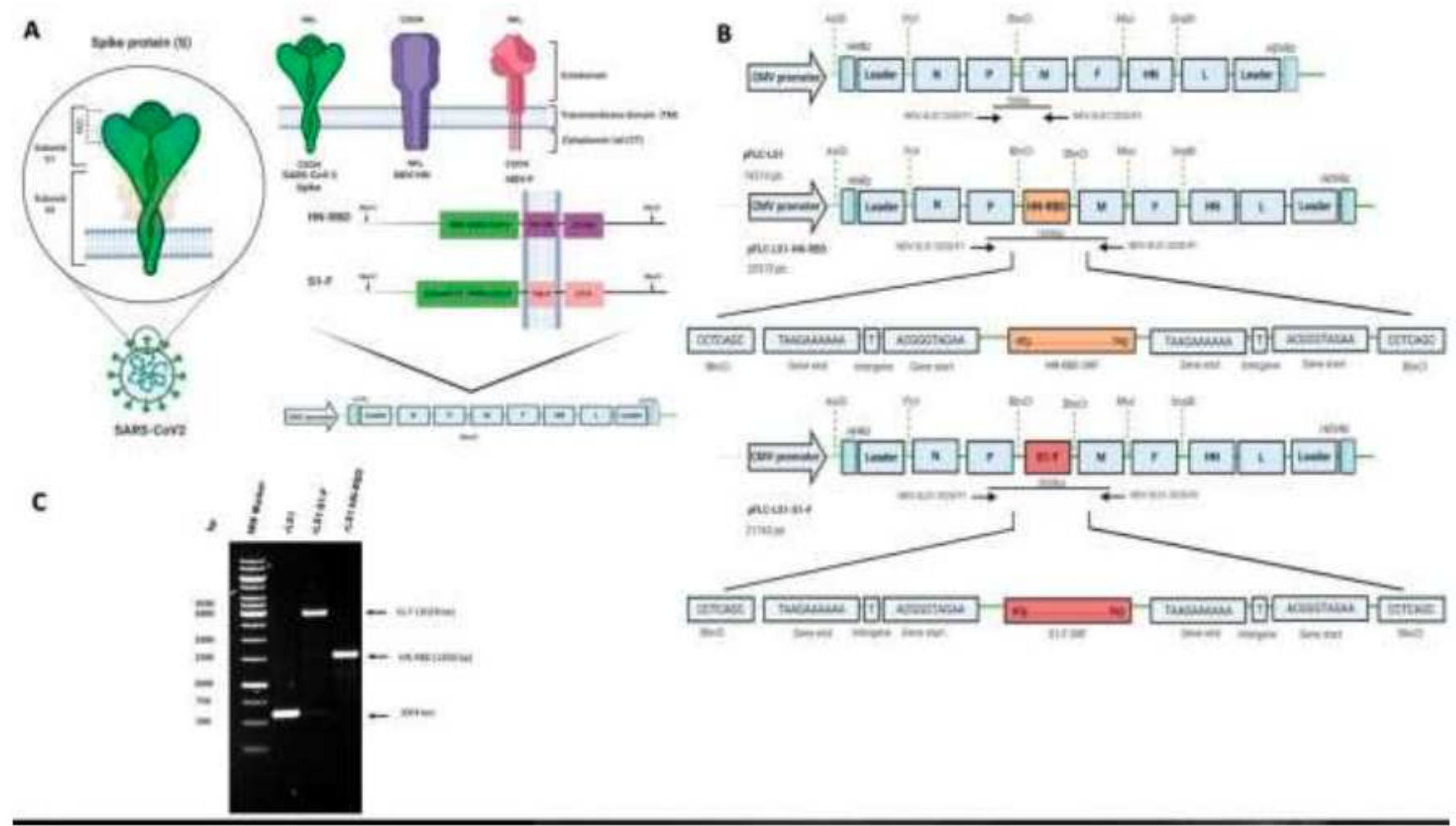

Figure 1

Please see the Manuscript PDF file for the complete figure caption 
A
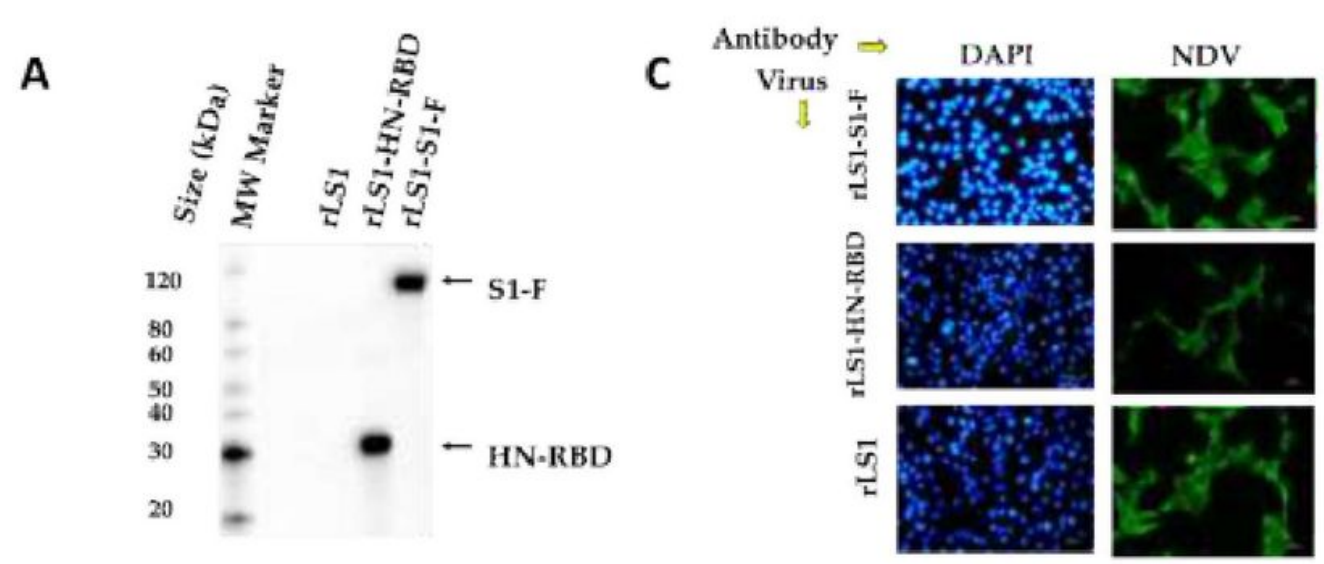

Anti- RBD
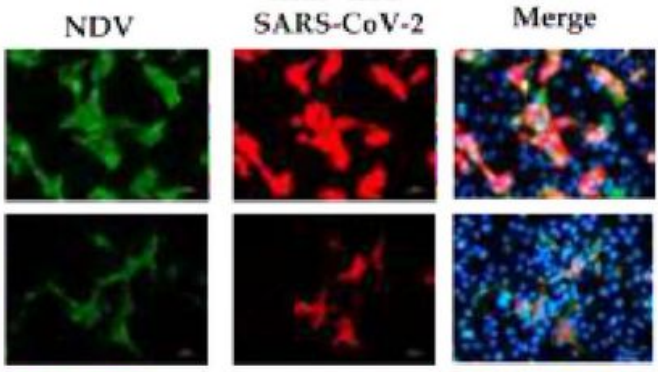

B
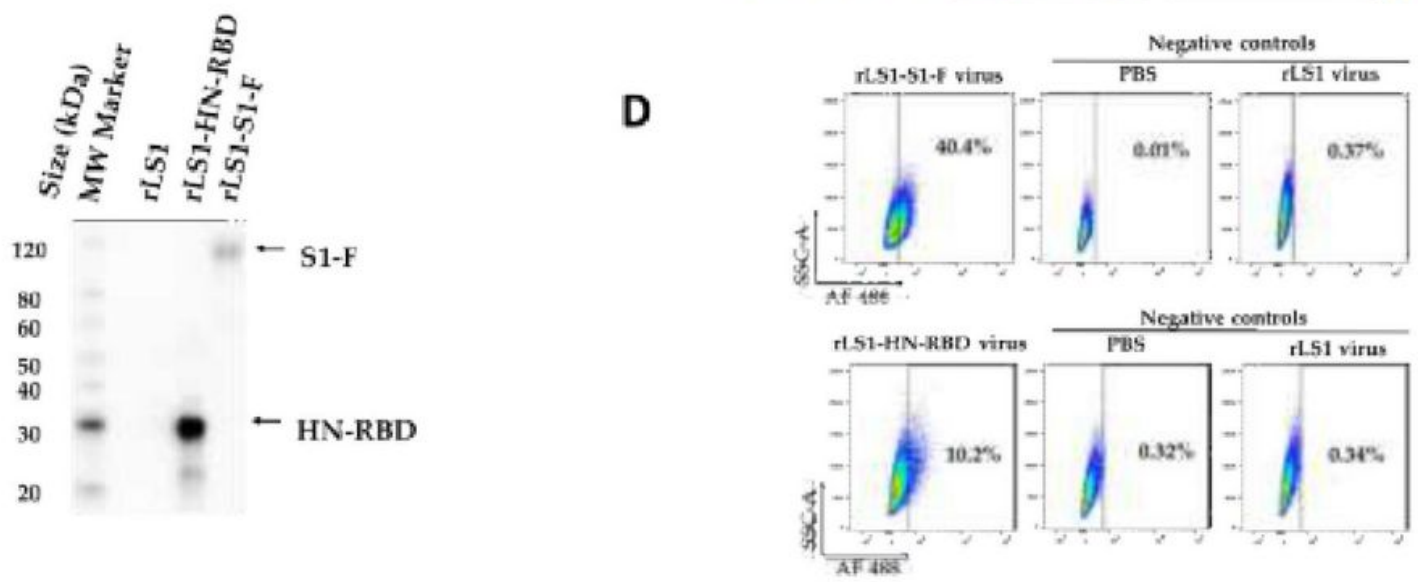

Figure 2

Please see the Manuscript PDF file for the complete figure caption 


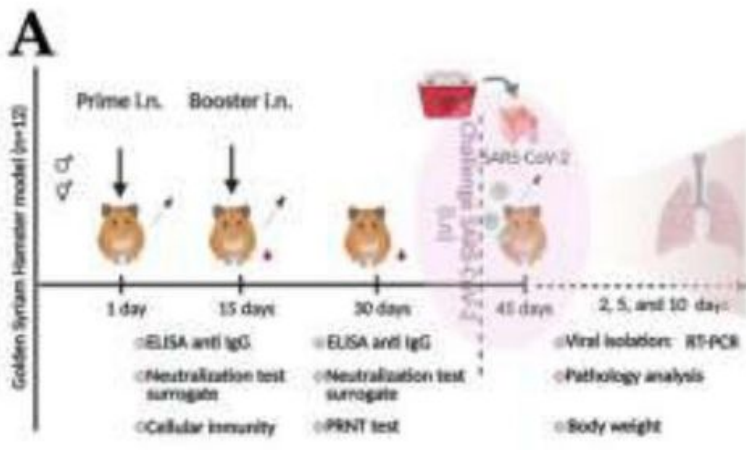

D

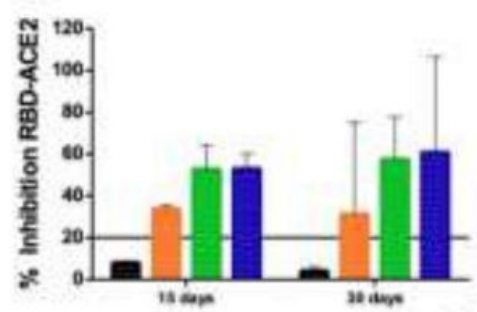

rLS1-S1-F/rLS1-HN-RBD

Days post-vaccination

- Negative control

NSTHN-Re

rSI-HN-RBD/rLS1-S1F

rLS1-S1-F

rLS1-HN-RBD

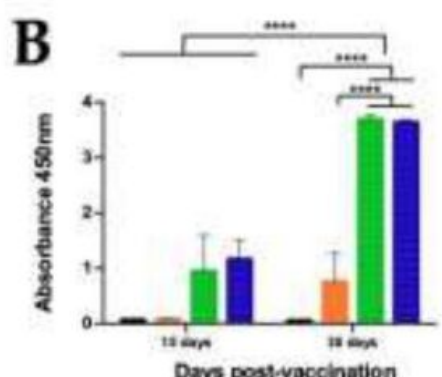

Days postrvacolnation
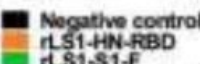

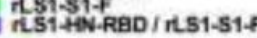

E

Negative control

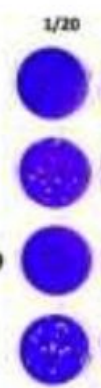

1/4a

$1 / 20$

1/250

$1 / 200$

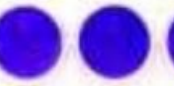

(6.) 89
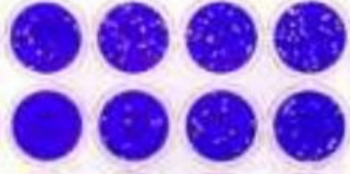

(1)

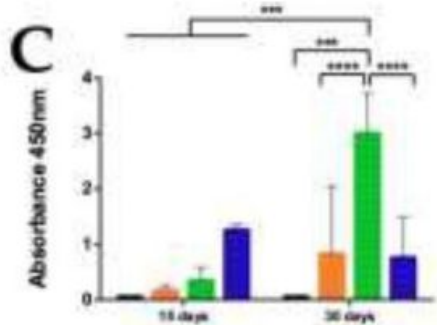

Days post-vaceination

Negative controi HS1+N-RBD

HS1 HNFBD/rS1-S1F

F

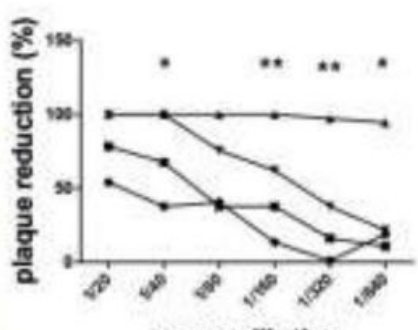

serum dilution

- rLS1-S1-FirLS1-HN-RBD

- ris1-51-F

- nLSiHN-RBD

- negative control

Figure 3

Please see the Manuscript PDF file for the complete figure caption 

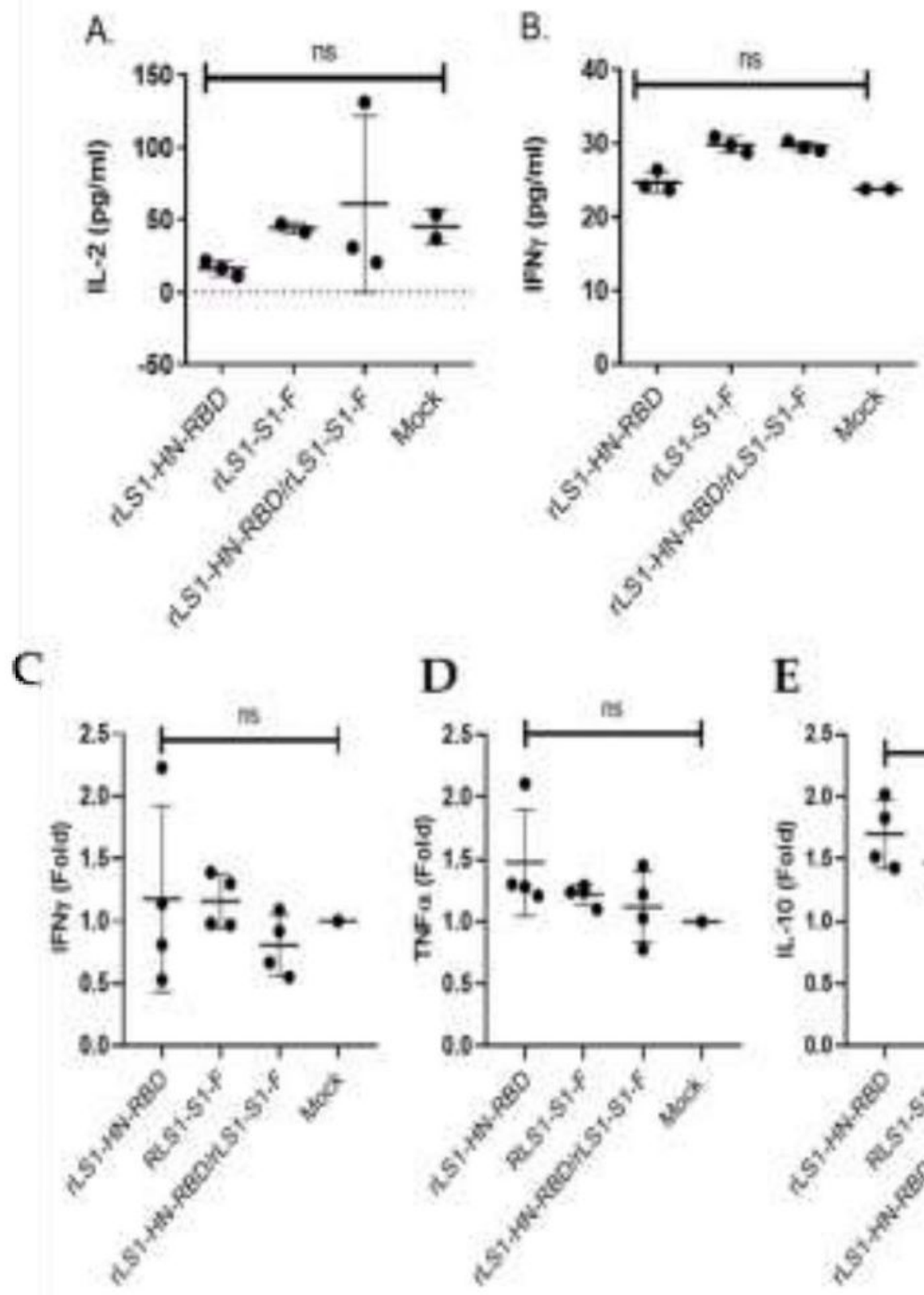

E

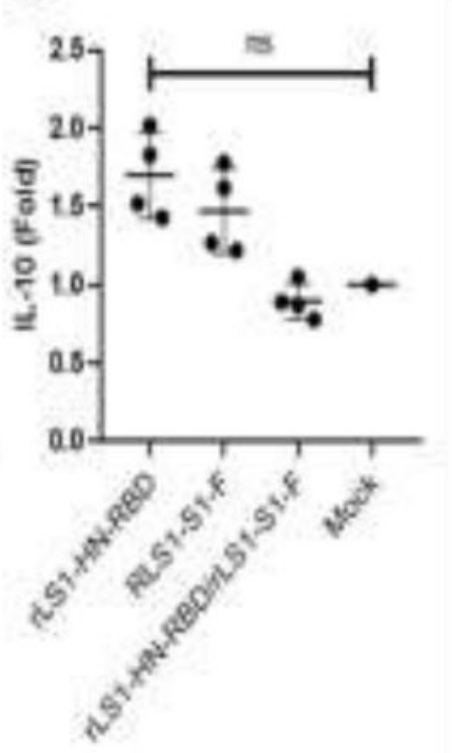

\section{Figure 4}

Please see the Manuscript PDF file for the complete figure caption 

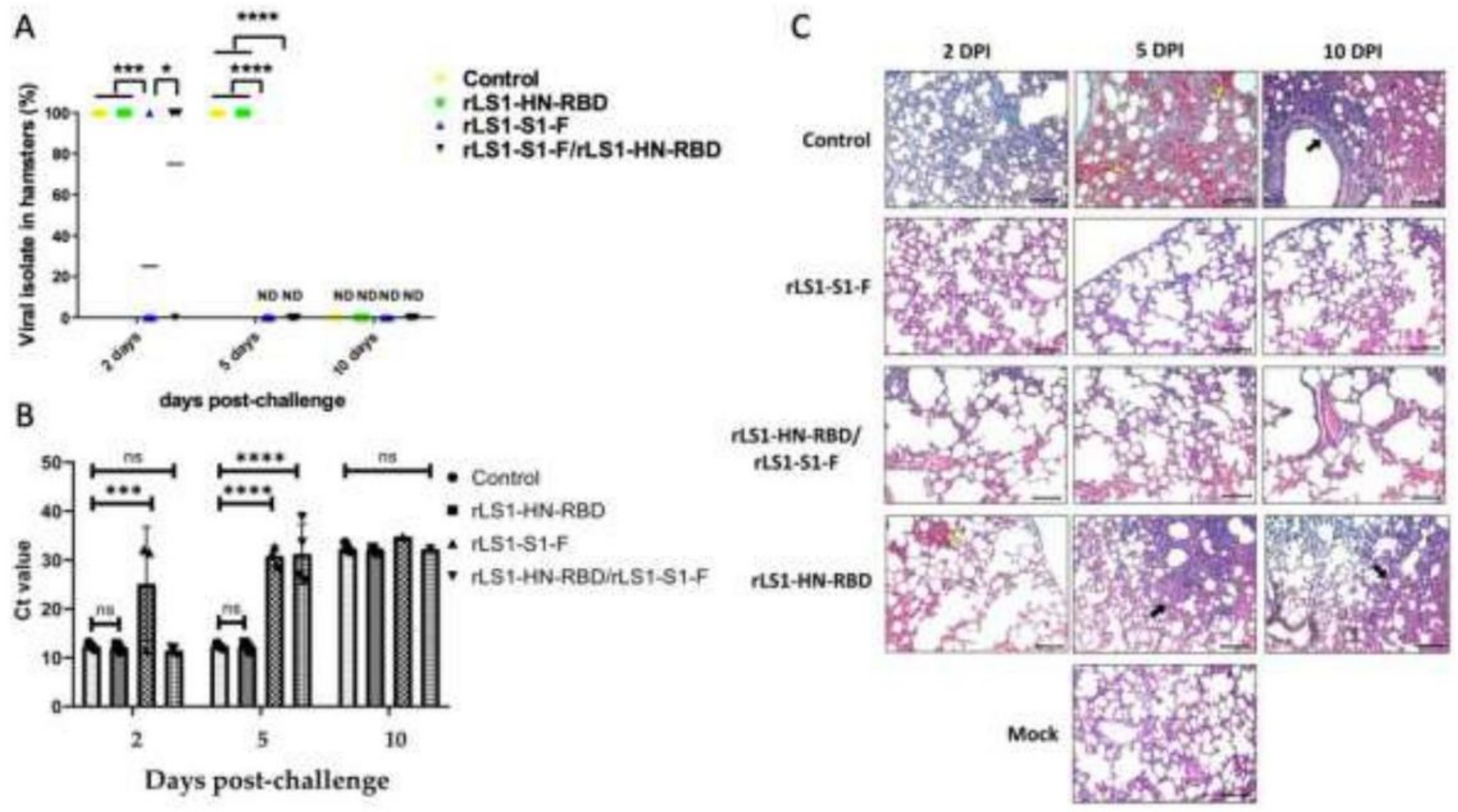

Figure 5

Please see the Manuscript PDF file for the complete figure caption 
A

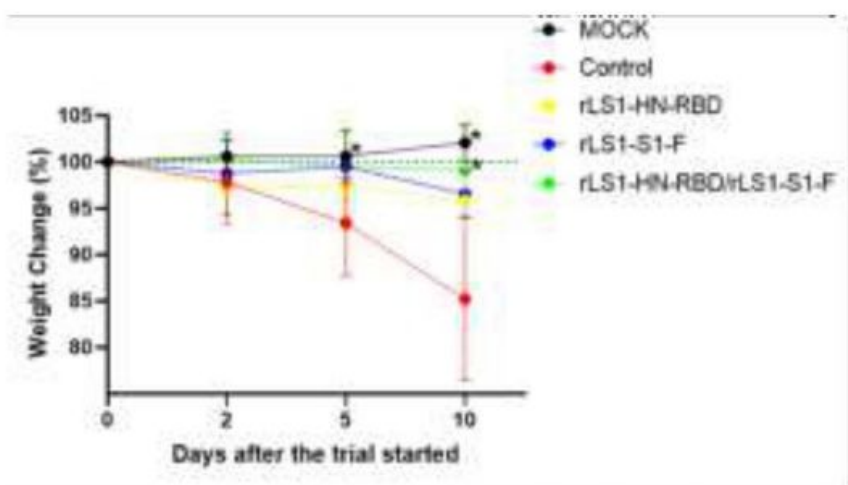

C

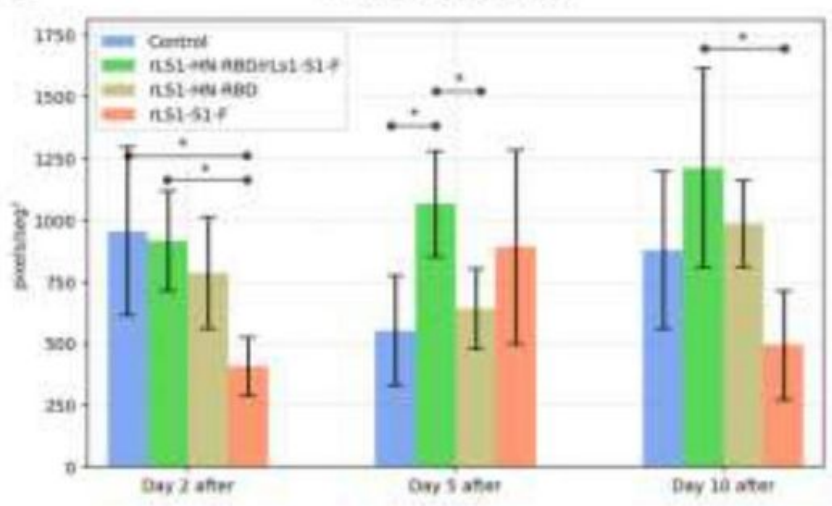

B

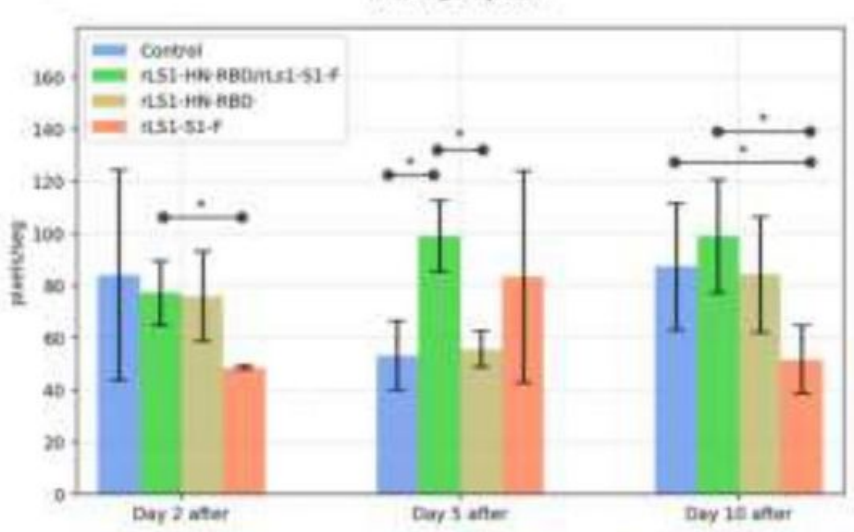

D Average displacement

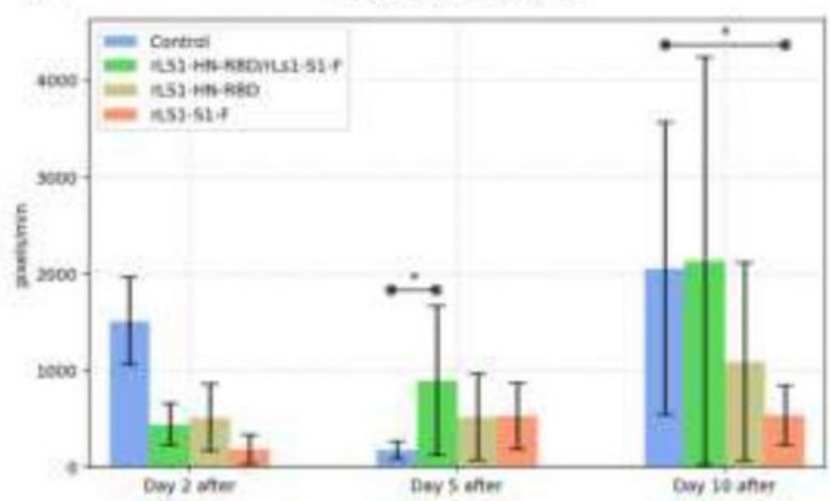

Figure 6

Please see the Manuscript PDF file for the complete figure caption

\section{Supplementary Files}

This is a list of supplementary files associated with this preprint. Click to download.

- SUPPLEMENTARYMATERIAL.pdf 